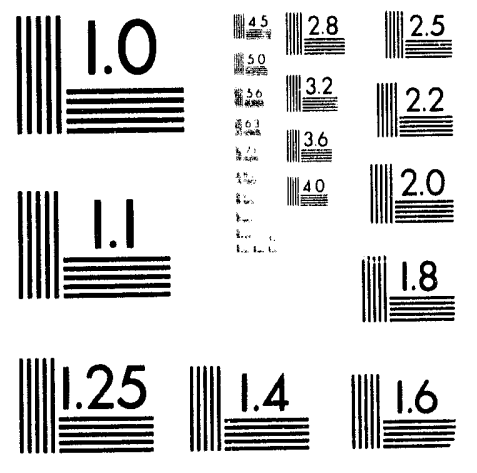



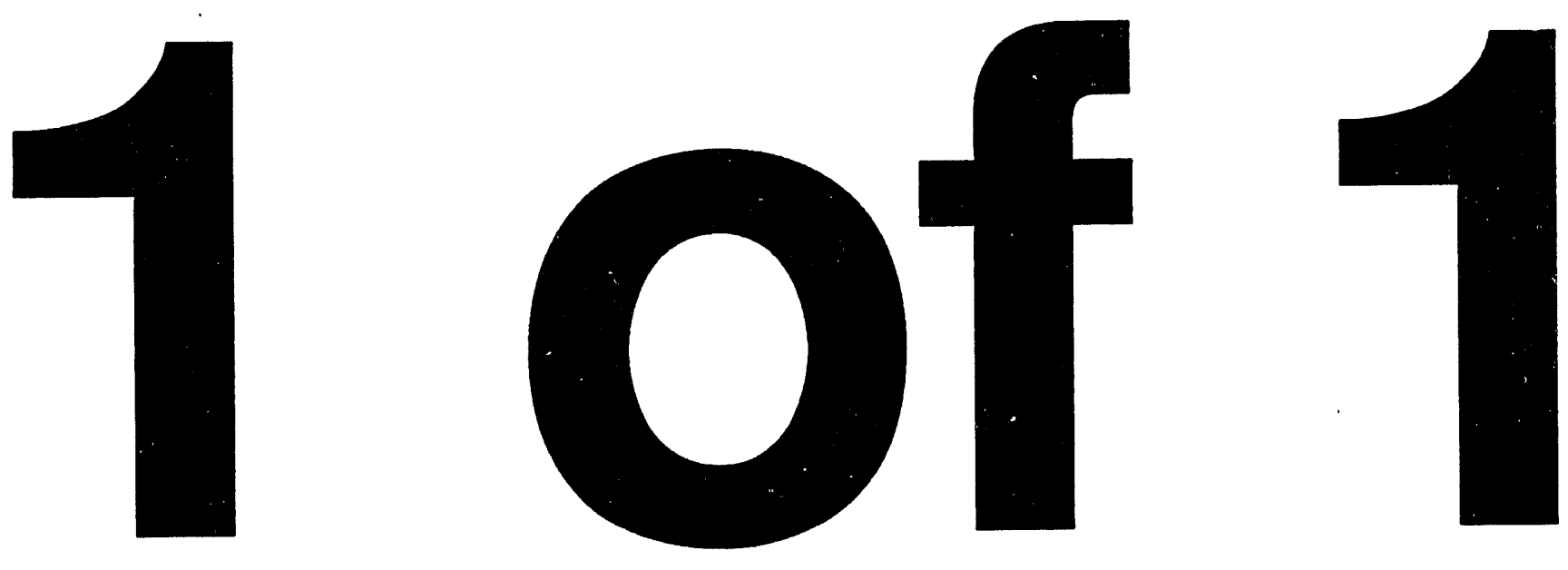
WSRC-TR-93-0209

Measurements of Radionuclides in Par Pond Sediments with an Underwater HPGe Detector(U)

Willard G. Winn

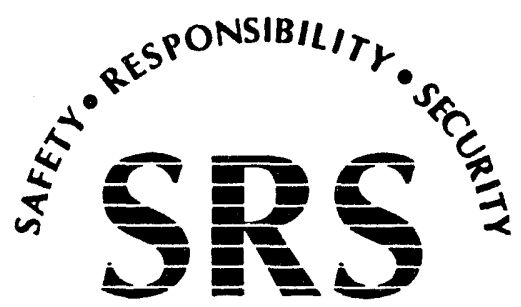

SAVANNAH RIVER SITE

Westinghouse Savannah River Company

Savannah River Technology Center

Aiken, SC 29808 


\section{Measurement of Radionuclides in Par Pond Sediments with an Underwater HPGe Detector}

\section{Contents}

Executive Summary

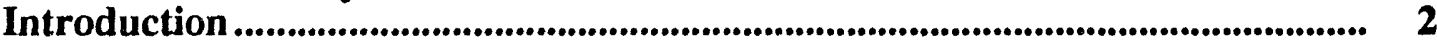

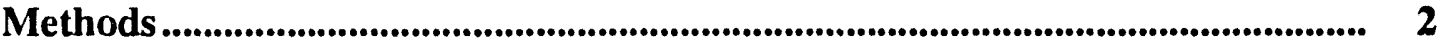

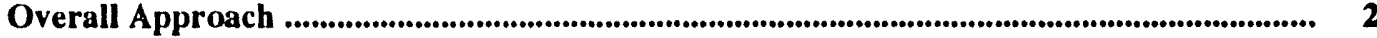

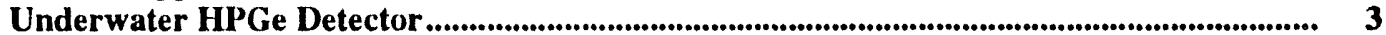

Ultra-Low-Level Gamma Spectrometry .......................................................................... 3

Measurements.............................................................................................................. 4

Underwater HPGe Detector ........................................................................................... 4

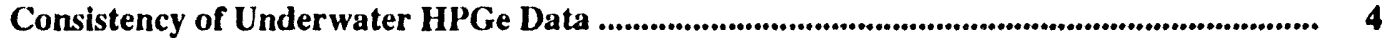

Low-Level HPGe Laboratory Measurements ................................................................................. 4

Data Transformation - Calibrations ............................................................. 5

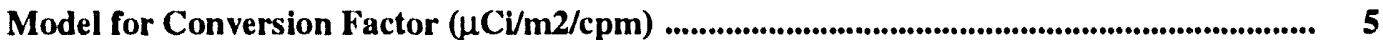

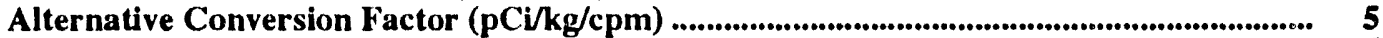

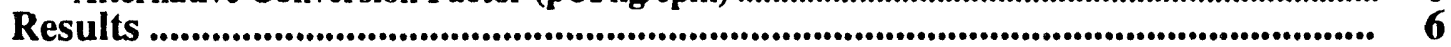

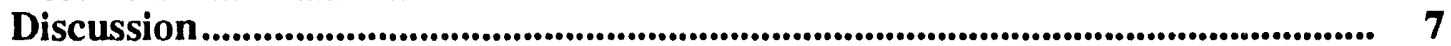

Acknowledgments . ....................................................................................... 8

References ......................................................................................................... 9

\section{Appendixes}

Appendix A. Raw Data - Underwater HPGe Measurements ..................................................... 27

Appendix B. Analysis of Vegetation and Temperature at Pond Bottom ........................................ 35

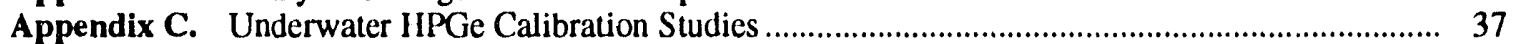




\section{List of Figures}

Figure 1. Acrial view of Par Pond, 10:25 AM, 21 August 1991.

Figure 2. Pontoon Boat equipped with HPGe Detector, associated electronics, and a hoist for lowering the detector into sampling position.

Figure 3. Detector assembly unit with IIPGe Detector Probe and Liquid Nitrogen Dewar................... 16

Figure 4. Measurement of ${ }^{137} \mathrm{Cs}$ Countrate for Transects. .................................................................... 17

Figure 5. Underwater HPGe Gamma Spectra of Sediment measured for (a) Hottest Point in the Pond and (b) Hottest Point in the Uncovered Pond Sediment. ............................................ 18

Figure 6. Transect 1 measurements of (a) ${ }^{137} \mathrm{Cs}$ and (b) Pond Depth. ............................................... 19

Figure 7. ${ }^{137} \mathrm{Cs}$ Measurements for Transects $1-9$ and their Smoothed Averages as a Function of Pond Depth.

Figure 8. Smoothed Averages of (a) Vegetation and (b) Sediment Temperature as a Function of Pond Depth.

Fïgure 9. Low-Level HIP(ie Spectra for (a) Sediment and (b) Vegetation Samples........................... 22

Figure 10. Geometry and Parameters used in Detector Efficiency Calculational Model..................... 23

Figure 11. Average Sediment Depth Dependence of (a) ${ }^{137} \mathrm{Cs}$ Probability and (b) Sediment Density.

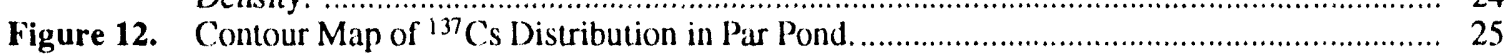

Figure 13. ${ }^{137} \mathrm{Cs}$ of Sediment Exposed as a Function of Drawdown Depth. ...................................... 26

Figure B-1 All Transect Measurements of (a) Vegetation and (b) Sediment Temperature. ................. 36

Figure C-1 EFFUGDPD Code Listing and Example. ......................................................................................... 39

Figure C-2 A/R Conversion Factors of Uniform ${ }^{137} \mathrm{Cs}$ and Sediment as a Function of ${ }^{137} \mathrm{Cs}$

Depth (h)

\section{List of Tables}

Table 1. Gamma-Emitting Radionuclides in Par Pond Sediment and Vegetation ............................. 10

Table 2. $\quad \mathrm{A} / \mathrm{R}(\mathrm{pCi} / \mathrm{kg} / \mathrm{cpm}){ }^{137} \mathrm{Cs}$ Conversion Factors for Par Pond Sediment.............................. 11

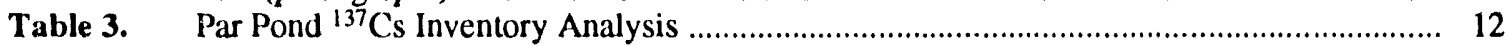

Table 4. Comparison of ${ }^{137} \mathrm{Cs}$ Estimates for Sediments of Lower Three Runs System ...................... 13

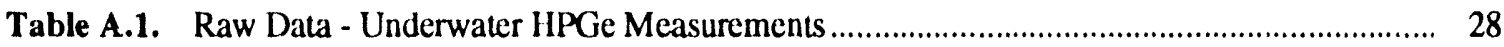

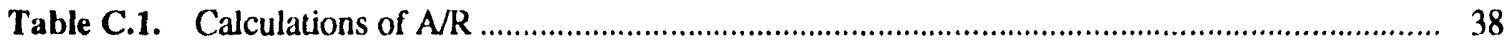




\section{Measurement of Radionuclides in Par Pond Sediments with an Underwater HPGe Detector}

\section{Executive Summary}

Savannah River Site (SRS) effluent gamma emitting radionuclides in Par Pond sediment were examined in situ with an underwater HPGe detector prior to and following a $19 \mathrm{ft}$ drawdown of the pond in 1991 to address dam repairs. These measurements provide a map of the ${ }^{137} \mathrm{Cs}$ concentrations of the pond sediment, indicating that $9.4 \pm 1.5 \mathrm{Ci}$ is exposed by the drawdown and that $46.6 \pm 7.2 \mathrm{Ci}$ is the entire pond inventory. The highest individual ${ }^{137} \mathrm{Cs}$ concentration was $25 \mu \mathrm{Ci} / \mathrm{m}^{2}$ for the exposed sediment and 50 $\mu \mathrm{Ci} / \mathrm{m}^{2}$ for the entire pond. The results are consistent with parallel studies conducted by SREL, as well as historical data.

Aside from ${ }^{137} \mathrm{Cs}$, the only other SRS-produced isotope observed was ${ }^{60} \mathrm{Co}$, with activity of only about $1 \%$ of that for ${ }^{137} \mathrm{Cs}$. This observation was also confirmed in grab samples of pond sediment and vegetation, which were returned to the laboratory for ultra-low-level gamma spectrometry analysis.

A special effort was required to calibrate the underwater HPGe detector, where both measurements and calculational models were used. The effects of sediment depth profiles for density and ${ }^{137} \mathrm{Cs}$ concentration were addressed in the calibration. Calibration factors for sediment surface concentrations $\left(\mu \mathrm{Ci} / \mathrm{m}^{2} / \mathrm{cpm}\right)$ and sediment mass concentrations $(\mathrm{pCi} / \mathrm{kg} / \mathrm{cpm})$ were obtained. In general, the $\mu \mathrm{Ci} / \mathrm{m}^{2} / \mathrm{cpm}$ factor is recommended, as the $\mathrm{pCi} / \mathrm{kg} / \mathrm{cpm}$ factor depends on the depth location of the sediment of interest. However, a pCi $/ \mathrm{kg} / \mathrm{cpm}$ factor, which is dependent on the depth within the sediment, is presented to address dose calculations that require it. 


\section{Introduction}

In March 1991 a depression was discovered on the downstream side of Par Pond Dam. Subsequently, plans were initiated to lower the pond level by $19 \mathrm{ft}$ to provide assurance against a dam failure and to allow for repairs. In this drawdown, a 528 hectare area of pond sediment was to be exposed, which is $50 \%$ of the normal 1057 hectare pond area when at full pool of 200 ft msl. Because these sediments were known to contain SRS-produced radionuclides, it was important to predict what their radiological impact would be prior to the drawdown, which was completed in September 1991.

The Par Pond sediments were expected to be dominated by ${ }^{137} \mathrm{Cs}$, based on historical data.' During R Reactor operations between 1954 and 1964, about $222 \mathrm{Ci}$ of ${ }^{137} \mathrm{Cs}$ were released to the Lower Three Runs System, which served to fill Par Pond in 1958. Because cesium favors collection in sediment rather than water, much of the ${ }^{137} \mathrm{Cs}$ remains in the pond sediment. As of 1991 , the released ${ }^{137} \mathrm{Cs}$ had decayed to $112 \mathrm{Ci}$, but only $71 \mathrm{Ci}$ was projected for Par Pond, Pond C, and the Lower Three Runs Creek System. Evaluations for associated smaller ponds and transport to the river account for the remainder. Because measurements indicated $12 \mathrm{Ci}$ of this
${ }^{137} \mathrm{Cs}$ was in Pond $\mathrm{B},{ }^{2}$ it was reasonable to consider that nearby Pond $\mathrm{C}$ and Lower Three Runs Creek would have at least this amount, suggesting an upper limit of $59 \mathrm{Ci}$ for Par Pond. Also, the large area of Par Pond suggested that at least half of the $71 \mathrm{Ci}$ might be expected to reside there, implying a lower limit of $35 \mathrm{Ci}$ for Par Pond. Thus, it could be reasonably predicted that Par Pond sediment should contain $35-59 \mathrm{Ci}$ of ${ }^{137} \mathrm{Cs}$ in 1991 .

The present work sought to validate the above Par Pond information, and to extend it to appraise the impact of the ${ }^{137} \mathrm{Cs}$ in sediments to be exposed upon drawdown. An underwater IIPGe detector was used to map the sediment ${ }^{137} \mathrm{Cs}$ on the pond bottom. A calibration factor was developed to convert the observed ${ }^{137} \mathrm{Cs}$ count rates to activity per sediment surface area. Initial work in July 1991 conducted mappings down to pond depths of $28 \mathrm{ft}$, to examine the sediments to be exposed with the $19 \mathrm{ft}$ drawdown to $181 \mathrm{ft} \mathrm{msl}$. Followup work during September to November examined the remainder of the pond, including maximum depths to $142 \mathrm{ft} \mathrm{msl}$, so that the earlier historical information could be validated.

\section{Methods}

\section{Overall Approach}

An aerial view of Par Pond in August 1991 during drawdown is shown in Figure 1, where beachlike areas about the pond are the exposed sediment. In July, prior to significant drawdown, an underwater HPGe detector mapped the ${ }^{137} \mathrm{Cs}$ detected in these sediments and those down to $172 \mathrm{ft} \mathrm{msl}$, and post-drawdown measurements mapped the rest of the pond sediments. Measurements were made with the detector on the pond bottom for representative transects of the pond at $3 \mathrm{ft}$ depth intervals. Selection of these transects was partly guided by 1962 mappings with an underwater G-M counter, ${ }^{3}$ and the resulting HPGe measurements were evaluated as being representative of the pond relative to the goals of the present study.
Additional data was also sought during the study. The sediment temperature and underwater vegetation were recorded for some of the underwater IIPGe measurements, to examine their consistency with previously noted ${ }^{137} \mathrm{Cs}$ correlations. ${ }^{2}$ At various locations, grab samples of sediment and underwater vegetation were collected for low-level gamma spectrometry at the Savannah River Technology Center/ Environmental Technology Section (SRTC/ETS) facilities. Such samples would help reveal any other SRS-produced gamma-emitting radionuclides in the pond environment. The sediment samples would also provide some information on the detector calibration; however, data from segmented core samples collected and analyzed by Savannah River Ecology Laboratory 
(SREL) provided the most detailed information for the calibration. ${ }^{4}$

\section{Underwater HPGe Detector}

The underwater HPGe detector operated froil a pontoon boat, as shown in Figure 2. The ditector has about $30 \%$ efficiency, relative to stindard comparison with a $3 " \times 3 " \mathrm{NaI}$ detector. Figure 3 is a photograph of the detector and its liçuid nitrogen dewar, both of which are contained within a screen housing. The bousing serves to protect the detector from impact damage and also defines the sediment counting geometry. The detector is lowered by a winch througb a trap door of the boat deck. An initial winch only reached depths of $30 \mathrm{ft}$, but a later replacement winch extended the measurements down $1058 \mathrm{ft}$, the deepest pond depth. With the detector lowered to the bottom sediment, one-minute IIPGe spectra were collected, yielding the count rate of the $662 \mathrm{keV}$ gamma of ${ }^{137} \mathrm{Cs}$. The pond depths were determined with a Lowrance depth finder.

Underwater operation of the HIPGe detector requires appropriate electrical cabling and venting of the evaporated liquid nitrogen. Both are provided through waterproof tubes extending from the detector to the deck. The detector preamp cables for power, high voltage, and signal output are all contained in a single tube. On the deck these cables are connected to standard NIM electronics, where the preamp signal pulses are amplified and collected as gamma spectra using a COMPAQ computer configured as a multichannel analyzer with an $\mathrm{ACE}^{\mathrm{TM}}$ card. A $5 \mathrm{kVA}$ gasoline generator energizes an uninterruptable power supply, which in turn provides reliable clean power for the electronics.

\section{Ultra-Low-Level Gamma Spectrometry}

Grab samples of vegetation and sediment were analyzed in the SRTC facilities, which include the Ultra Low Level Counting Facility (ULLCF) and the Underground Counting Facility (UCF). ${ }^{5}$ The vegetation samples were examined in the ULLCF, and the sediment samples were analyzed in the UCF. Vegetation samples were ashed to smaller volumes of $5-10 \mathrm{~cm}^{3}$ to enhance detection efficiency; then they were counted for about $6 \mathrm{hr}$ within standard $33 \mathrm{~mm}$ diameter counting vials. Sediment samples of about $300 \mathrm{~g}$ were placed in standard $64 \mathrm{~mm}$ diam counting vials, and counted overnight or longer in the UCF.

The ULLCF is a ground-level counting facility contained within a chamber with 12 in walls of pre-WWII steel. The air of the facility is filtered to remove natural background particulates. HPGe detectors with standard efficiencies ranging from $8.8 \%$ to $16.0 \%$ were used in counting the vegetation samples.

The UCF is $50 \mathrm{ft}$ below ground and constructed with low background materials. Pre-WWII steel comprises the 4 in walls of the counting chamber, which is shielded by 4-7 ft of specular hematite. The total overburden is equivalent to $104 \mathrm{ft}$ of water shielding, which reduces the cosmic background by an order of magnitude. The facility operates as a Class 10,000 clean room, whereby airborne particulates are removed by filtering. The very stable spectrometry electronics use an uninterruptable power supply to protect against data losses during extended counting times. A HPGe detector with $90 \%$ standard efficiency counted the sediment samples. To remove radon background, the shielded sample cavity of the detector is purged with nitrogen that evaporates from its dewar. The detector is also enclosed in an active plastic scintillator shield, which vetoes counting during short intervals in which cosmic-ray background is detected. ${ }^{6}$ 


\section{Measurements}

\section{Underwater HPGe Detector}

Measurements on Par Pond were conducted for the 9 transects given in the map of Figure 4 . Additional measurements in the mouth of the middle arm (transect 10, not shown on map), examined a maximum activity area known from earlier studies. The raw data from these measurements are recorded in Appendix $A$, where each measurement is characterized by its location coordinates, pond depth, and ${ }^{137} \mathrm{Cs}$ count rate measured by the underwater IIPCie detector. For measurements at pond depths down to $28 \mathrm{ft}$, sediment temperature and vegetation observations are also recorded. Only one minute of counting was required to obtain suitable count-rate statistics.

Gamma-ray spectra measured with the underwater IIIYGe detector are given in Figure 5 . Aside from ${ }^{137} \mathrm{Cs}$, the only other man-made radionuclide detected was ${ }^{60} \mathrm{Co}$. This was also the case for the vegetation and sediment samples that were returned to the laboratory for counting.

For an individual transect, the count-rate data scatter noticeably, as shown in the example in ligure 6; however, trends in the data are still recognizable. Overall, each transect shows that sediment ${ }^{137} \mathrm{Cs}$ increases with pond depth. Jigure 7 displays this overall trend better by plotting the ${ }^{137} \mathrm{Cs}$ count rates of all transects of ligure 4 as a function of pond depth. Smoothed normal and geometric averages of count rates exhibit the trend more clearly in Figure 7. Here, each average includes a single point and 18 adjacent points (9 above and 9 below) at monotonic depths. Corresponding smoothed normal-average depths are assigned to each smoothed count-rate.

\section{Consistency of Underwater HPGe Data}

Various quality checks were applied to appraise the measurements. Suspiciously low count rates were remeasured after slight repositioning of the detector on the bottom, to assure that obstructions such as stumps did not displace the detector from the bottom sediment. After each measurement, any muddy sediment sticking to the bottom screen was removed to prevent crosscontaminating measurements from one site to another.

Tests were also conducted to appraise the adequacy of the data for its intended application. As shown in Iigure $4,{ }^{137} \mathrm{Cs}$ count-rate averages for half-transects (shore-to-deepest depth) were calculated to examine variations as a function of pond location. Reasonable monotonic trends with location are observed in the ligure, and the maximum/minimum for these values is only a factor of 4. Thus, the transects were appraised as providing a representative sampling of the pond.

In ligure 7 a small dip in count rate is noted in the smoothed data for sediment depths of about $17 \mathrm{ft}$. Such observations have been noted earlier and are correlated with the limit of underwater vegetation. ${ }^{2}$ Such a correlation also existed in the present study, as noted in Iigure 8a, where the average occurrence of observed vegetation is plotted as a function of depth. The $17 \mathrm{ft}$ depth for the vegetation limit also corresponds to the point of rapid decrease in dissolved oxygen, deduced from direct measurements ${ }^{3}$ and the corresponding dropoff in the average temperature measurements shown in Figure 8 b. Details on the average vegetation and temperatures of Figure 8 are given in Appendix B.

\section{Low-Level HPGe Laboratory Measurements}

Measurements for the samples returned to the ULLCF and UCF are summarized in Table 1. Other than ${ }^{137} \mathrm{Cs}$, the only man-made isotope observed was ${ }^{60} \mathrm{Co}$, which had only about $1 \%$ the intensity of the ${ }^{137} \mathrm{Cs}$. The ${ }^{60} \mathrm{Co}$ and ${ }^{137} \mathrm{Cs}$ have respective half-lives of 5.3 and 30.2 years, which are much longer than other gamma-emitting nuclides that were released to the pond about 30 years earlier. Example gamma spectra for these samples are given in Figure 9. It should be noted that the present studies were not appropriate for detecting long-lived pure beta isotopes such as ${ }^{90} \mathrm{Sr}$ and low-yicld gamma emitters such as isotopes of $\mathrm{U}$ and $\mathrm{Pu}$. 


\section{Data Transformation - Calibrations}

The above ${ }^{137} \mathrm{Cs}$ count-rate (cpm) measurements with the underwater HPGe detector required transformation to activity/area $\left(\mu \mathrm{Ci} / \mathrm{m}^{2}\right)$, before the pond inventory of ${ }^{137} \mathrm{Cs}$ could be quantified. In actuality, each sediment measurement location should have a unique conversion factor $\left(\mu \mathrm{Ci} / \mathrm{m}^{2} / \mathrm{cpm}\right)$, because the factor depends on the depth profile of ${ }^{137} \mathrm{Cs}$ within the sediment and sediment density profile. It was suggested that peak/Compton correlations of the measured spectra might guide individual corrections. However, the overall low counting statistics implied that this approach would be unfruitful. It was decided to develop a single global conversion factor, which would be modeled for a representative average sediment. Although an error would be introduced for individual measurements converted with this factor, the errors for numerous averaged measurements, as given in Figure 7, tend to cancel.

\section{Model for Conversion Factor $\left(\mu \mathrm{Ci} / \mathrm{m}^{2} / \mathrm{cpm}\right)$}

The conversion factor for ${ }^{137} \mathrm{Cs}$ activity required efficiency calibrations for its $662 \mathrm{keV}$ gamma. Referring to Figure 10, the efficiency for a point in the sample is

$$
\epsilon(r, z)=\epsilon_{A}(0,0) \frac{z_{0}{ }^{2}}{\left(z+z_{0}\right)^{2}+r^{2}} \exp \left(-\mu_{w} 1_{w}-\bar{\mu}_{(}(z) l_{0}\right)(1)
$$

where $\epsilon_{A}(0,0)$ is the point ( $\left.r=0, z=0\right)$ efficiency measured in air, and $\mu_{\mathrm{w}}$ and $\bar{\mu}_{\mathrm{s}}(z)$ are the gamma allenuation coefficients for water and sediment. Sediment core measurements ${ }^{4}$ provided an average density $\mathrm{p}_{\mathrm{S}}(\mathrm{z})$ so that

$\bar{\mu}_{\mathrm{s}}(\mathrm{z})=\mathrm{z}^{-1} \int_{0}^{z} \mu_{s}\left(\mathrm{z}^{\prime}\right) \mathrm{d} \mathrm{z}^{\prime}=\mathrm{z}^{-1} \int_{0}^{z} \mathrm{p}_{\mathrm{s}}\left(\mathrm{z}^{\prime}\right) \sigma \mathrm{d} \mathrm{z}^{\prime}$

where $\sigma$ is the mass attenuation coeflicient.
The ${ }^{137} \mathrm{Cs}$ count rate $R$ is an integral over the volume producing the rate,

$R=A \int_{0}^{h} \int_{0}^{\mathrm{p}} \overline{\mathrm{P}}(\mathrm{z}) \mathrm{I}_{\gamma} \in(\mathrm{r}, \mathrm{z}) 2 \pi \mathrm{rdrdz}$,

wherein the gamma emission rate per sediment volume is $A \bar{P}(z) I_{\gamma}$ where $A$ is the ${ }^{137} \mathrm{Cs}$ decay rate per sediment surface area, $\bar{P}(z)$ is the average ${ }^{137} \mathrm{Cs}$ probability per $z$-increment, and $I_{\gamma}$ denotes the $662 \mathrm{keV}$ gammas per ${ }^{137} \mathrm{Cs}$ decay. Twelve individual $P(z)$ from core data ${ }^{2}$ yiclded $\overline{\mathrm{P}}(\mathrm{z})$, which defined integral limit $\mathrm{h}=38 \mathrm{~cm}$. With radial limit $a=70 \mathrm{~cm}$, integral calculations were within $1 \%$ of those for $a=\infty$. Using this information in Eq.(3) yiclded a value of $A / R=$ $0.0171 \pm 0.0027 \mu \mathrm{Ci} / \mathrm{m}^{2} / \mathrm{cpm}$ for transforming count rates to activities, where the $A / R$ uncertainty was oblained as follows.

The average depth distributions for ${ }^{137} \mathrm{Cs}$ probability $\overline{\mathrm{P}}(\mathrm{z})$ and sediment density $\mathrm{p}_{\mathrm{s}}(\mathrm{z})$ are given in Figure 11. The error for the $A / R$ conversion factor was calculated by examining the conversion factors for the individual $P(z)$ used in the average. The variations in the twelve $\mathrm{p}_{\mathrm{s}}(\mathrm{z})$ were negligible relative to those of $\mathrm{P}(\mathrm{z})$. Further details on the calculations, including the code describing the numerical integrations, are given in Appendix $\mathrm{C}$.

\section{Alternative Conversion Factor (pCi/kg/cpm)}

Some of the preliminary analyses of these studies had used a ${ }^{137} \mathrm{Cs}$ conversion factor in units of $\mathrm{pCi} / \mathrm{kg} / \mathrm{cpm}$, which was determined by using grab samples taken at locations where the underwater detector had measured ${ }^{137} \mathrm{Cs}$ count rates. These grab samples $(15.6 \mathrm{~cm} \times 15.6 \mathrm{~cm}$ area, $8.6 \mathrm{~cm}$ depth) were taken with a dredge, homogenized, and returned to the laboratory for analysis in the UCF to determine their ${ }^{137} \mathrm{Cs}$ concentrations. The resulting ratios of concentration ( $\mathrm{pCi} / \mathrm{kg}$ ) to count rate $(\mathrm{cpm})$ yiclded an average ratio of $85 \mathrm{pCi} / \mathrm{kg} / \mathrm{cpm}$. 
Although a $p \mathrm{Ci} / \mathrm{kg} / \mathrm{cpm}$ conversion factor is casy to measure, it is generally inappropriate for accurately describing the ${ }^{137} \mathrm{Cs}$ within the sediment. Because ${ }^{137} \mathrm{Cs}$ varies with sediment depth, as shown in ligure 11a, the grab sample provides only an average $\mathrm{pCi} / \mathrm{kg}$ for the sediment sampled. No information is obtained for the ${ }^{137} \mathrm{Cs}$ at deeper depths into the sediment. Also, it is difficult to assure that the sediment sample is taken exactly at the same location as the underwater IIPGie. The preliminary $85 \mathrm{pCi} / \mathrm{kg} / \mathrm{cpm}$ conversion factor did provide rough estimates (factor of 2 low) of the Par Pond ${ }^{137} \mathrm{Cs}$ inventory, which were primarily limited by the uncertainty in the effective sediment thickness.

Overall, conversion factors using area concentrations are recommended over those using volume or mass concentrations, because the latter are dependent on depth lecation within the sediment. The depth effect for Par Pond sediments is illustrated in Table 2 , where the area concentration conversion factor for this work has been transformed to mass concentration factors as a function of depth. Table 2 utilizes the ${ }^{137} \mathrm{Cs}$ probability and sediment density profiles of Figure 7 to yield the ${ }^{137} \mathrm{Cs}$ conversion for wet sediment. This profile information, as well as that for dry sediment, are included in the table. The table illustrates that a wet grab sample retrieved down to a sediment depth of $10 \mathrm{~cm}$ would include sediment with conversion factors ranging from 57 to $154 \mathrm{pCi} / \mathrm{kg} / \mathrm{cpm}$, yiclding an overall average of $108 \mathrm{pCi} / \mathrm{kg} / \mathrm{cpm}$. If the sediment were uncovered in drawdown and dried out, the top layer would laave a conversion factor of $456 \mathrm{pCi} / \mathrm{kg} / \mathrm{cpm}$. Thus, an appropriate mass conversion factor cannot not be thought of as a single number; it must be selected based on both the sediment location and its condition. For example, dose evaluations of the exposed Par Pond sediment required different mass conversion factors for the doses an individual would receive from inhaling surface dust and plowing up the sediment.

\section{Results}

All ${ }^{137}$ Cs count rates (cpm) were converted to area density $\left(\mu \mathrm{Ci} / \mathrm{m}^{2}\right)$ to develop the contour plot of ligure 12. The contour plot smooths the data and uses interpolations between the transects and the pond boundary. This boundary is assumed to have fallout levels of ${ }^{137} \mathrm{Cs}$, which are effectively negligible relative to the contour analysis. Although the transects shown in ligure 4 are somewhat distant from each other, their ${ }^{137} \mathrm{Cs}$ activity trends did not indicate any unwicldy fluctuations that would invalidate the general trends of the interpolations used in the plot. These assumptions are also supported by 1962 sediment mappings with an underwater $(\mathrm{i}-\mathrm{M}$ detector. ${ }^{3}$ Overall, the contour map gives the general distribution of the ${ }^{137} \mathrm{Cs}$ in Par Pond, but some "hot points" are removed in the averaging. In particular, for sediment that became exposed, the smoothing did not distinguish the largest individual "hot point" of $25 \mu \mathrm{Ci} / \mathrm{m}^{2}(1440 \mathrm{cpm}$, transect 3). By contrast, the pond maximum "hot point" of $50 \mathrm{\mu Ci} / \mathrm{m}^{2}(2913 \mathrm{cpm}$, transect 10$)$ is distinguished, as other nearby "hot points" serve to definc a "hot spot" as opposed to an isolated "hot point". Better map resolution that would reveal more localized ${ }^{137} \mathrm{Cs}$ variations for the entire pond would have required considerably more measurements than the 200 acquired in the present study.

The drawdown exposure of ${ }^{137} \mathrm{Cs}$ was of prime intere: it in this study. The count-rate data used for the contour plot were averaged for areas contained within 3 meter depth contours. These average count rates were then transformed to $\mu \mathrm{Ci} / \mathrm{m}^{2}$ and multiplied by their corresponding sediment area $\left(\mathrm{m}^{2}\right)$ to yield the ${ }^{137} \mathrm{Cs}$ between the Par Pond depth contours. Successively adding the ${ }^{137} \mathrm{Cs}$ for deeper contours yields the ${ }^{137} \mathrm{Cs}$ exposed as a function of drawdown depth, as summarized in Table 3 and Figure 13. Using the plot, a value of $9.4 \pm 1.5 \mathrm{Ci}$ of ${ }^{137} \mathrm{Cs}$ is exposed for the drawdown to $181 \mathrm{ft}$ msl. The plot shows that the total inventory is $46.6 \pm 7.2 \mathrm{Ci}$. 


\section{Discussion}

The above study was a component of related studies for evaluating the sediment in Par Pond. In particular, the work by SRISL on segmented sediment cores of Par Pond has served to provide an independent estimate of the ${ }^{137} \mathrm{Cs}$ pond inventory. ${ }^{4}$ The results, still preliminary, compare favorably with those of the present work, as well as those from the historical predictions, as summarized in lable 4 . The present study also updates values given in a recent summary report on cesium isotopes in the SRS environment. ${ }^{1}$ These values were based on a less refined analysis of the underwater IIPGic measurements, ${ }^{7}$ which had less core data for the average ${ }^{137} \mathrm{Cs}$ depth profile $\bar{P}(\mathrm{z})$ and assumed a constant sediment density profile for $\mathrm{p}_{\mathrm{s}}(z)$. The updated values also include preliminary results for recent underwater HPGe measurements of Pond C sediments. ${ }^{8}$ Initial publication of the Pond $\mathrm{C}$ values ${ }^{8}$ and the refined Par Pond values ${ }^{9}$ occurred after the summary report ${ }^{1}$ was issued.

The excellent consistency of the above estimates for ${ }^{137} \mathrm{Cs}$ in Par Pond strongly argue that the
$9.4 \pm 1.5 \mathrm{Ci}$ for the exposed sediment is a reliable number. 'This exposed sediment has also heen observed with Nal overflight mappings of the area by EG\&G/Iinergy Measurements, ${ }^{10}$ but these overflight studies generally provide only relative count rate data for ${ }^{137} \mathrm{Cs}$. The data may be transformed to $\mu \mathrm{Ci} / \mathrm{m}^{2}$ by normalizing it to the $9.4 \mathrm{Ci}$ deternined for the exposed sediment; comparison with the contour map of Figure 12 will also be useful for this normalization. ${ }^{10}$

Various future options for Par Pond are being examined, including further drainage of the pond or refilling it. Decisions on these options may be guided by the results of the present work. The contour map and drawdown plot provide a reasonable overview of the ${ }^{137} \mathrm{Cs}$ distribution in the pond, and "hot point" values may be used for extreme scenarios. Also, the calibration results guide appropriate selection of ${ }^{137} \mathrm{Cs}$ countrate/activity conversion factors, which differ according to specific dose evaluations. 


\section{Acknowledgments}

The author thanks F.W. Wicker of SREL and his graduate students, D. Niquette and J. Seel, for their cooperative efforts in the field and sharing data from their studies of Par Pond. In particular, their segmented core data on the sediments were invaluable in developing appropriate calibrations for the underwater IIPGe detector.

W.W. Bowman and M.M. Pendergast are thanked for generating the ${ }^{137} \mathrm{Cs}$ contour map of Par Pond from the underwater IIPGe data. D.W. Hayes helped design the early phases of study, providing useful background data. Included in the data are the areas between depth contours, which were provided by J.E. Pinder of SREL. W.D. Dalton is thanked for counting the vegetation samples in the ULI.CF,
E.M. Miller is thanked for coordinating assignments of ETS technicians who assisted in the field measurements with the underwater HIPGe detector. The technicians include (.D. Ouzts, II.T. Wilson, R.R. Penix, R.W. Johnson, R.J. Roseberry, H.L. Hayes, W.B. Matthews, and R.J. Tunstall. In addition, C.D. Ouzts is thanked for counting the sediment samples in the UCF.

This document was prepared in connection with work done under Contract No. DE-AC0989SR 18035 with the U.S. Department of Energy. By acceptance of this document, the publisher and/or recipient acknowledges the U.S. Government's right to retain a nonexclusive, royalty-free license in and to any copyright covering this document, along with the right to reproduce and to authorize others to reproduce all or part of the copyrighted material. 


\section{References}

1. W.II. Cariton, L.R. Bauer, A.G. Evans, L.A. Geary, C.E. Murphy, Jr., J.E. Pinder, and R.N. Storm, "Cesium in the Savannah River Site Environment", WSRC-RP-92250 (March, 1992).

2. I.W. Whicker, J.E. Pinder, J.W. Bowling, J.J. Alberts, and 1.L. Brisbin, Jr., "Distribution of Long-Lived Radionuclides in an Abandoned Reactor Cooling Reservoir", Ecological Monograms, 60, pp $471.476(1990)$.

3. D.W. Ilayes, "Inventory and Concentration of Cs.137 and Tritium in Par Pond and lower 'Three Runs System", SRI,-ETS-910327 (July 15, 1991).

4. I.W. Whicker, D. Niquelte, and J. Seel, Savannah River Ecology Laboratory, Direct Communications (1991-1992).

5. W.G. Winn, W.W. Bowman, and A.L. Boni, "Ultua-Clean Underground Counting lacility for Low-Level Environmental Sumples", DP.1747 (September, 1987)
6. W.G. Winn, "Gamma-Ray Spectrometry of LDEF Samples", WSRC-RD-91-16 (February, 1992).

7. W.G. Winn, "Measurements of Cs-137 in Par Pond Sediment with an Underwater HPGe Detector",SRL-ETS-91-0388 (November 16, 1991)

8. W.G. Winn, "Preliminary Summary - Pond C Measurements with Underwater HPGe Detector", SRTC-ETS-93-040 (February 9, 1993).

9. W.G. Winn, "Evaluation of ${ }^{137} \mathrm{Cs}$ in Pond Sediment with an Underwater HPGe Detector", Trans. Am. Amer. Nuc. Soc., 66, pp 32-34 (1992).

10. E.L. Feimster, EG\&G Energy Measurements, Las Vegas, Nevada, Direct Communications (January, 1993). 
Table 1. Gamma-Emitting Radionuclides in Par Pond Sediment and Vegetation

\section{Sediment}

\begin{tabular}{|c|c|c|c|}
\hline Site & ${ }^{60} \mathrm{Co}$ & ${ }^{137} \mathrm{Cs}$ & ${ }^{60} \mathrm{Co} /{ }^{137} \mathrm{Cs}$ \\
\hline & $(\mathrm{pCi} / \mathrm{g})$ & $(\mathrm{pCi} / \mathrm{g})$ & $(\%)$ \\
\hline 3/East & $0.169 \pm 0.003$ & $27.00 \pm 0.05$ & $0.63 \pm 0.01$ \\
\hline 4/South & $0.023 \pm 0.001$ & $4.53 \pm 0.02$ & $0.52 \pm 0.02$ \\
\hline 5/North & $1.100 \pm 0.010$ & $74.80 \pm 0.10$ & $1.47 \pm 0.02$ \\
\hline 5/South & $0.797 \pm 0.007$ & $89.70 \pm 0.10$ & $0.89 \pm 0.01$ \\
\hline 8-9/South & $0.179 \pm 0.004$ & $33.90 \pm 0.10$ & $0.53 \pm 0.01$ \\
\hline 9/North & $0.003 \pm 0.001$ & $0.23 \pm 0.01$ & $1.46 \pm 0.49$ \\
\hline $10 /$ South & $1.310 \pm 0.010$ & $136.00 \pm 1.00$ & $0.96 \pm 0.01$ \\
\hline Average & $\ldots a$ & $\ldots a^{a}$ & $0.92 \pm 0.15^{b}$ \\
\hline
\end{tabular}

\section{Yegetation $^{c}$}

\begin{tabular}{|c|c|c|}
\hline Site & ${ }^{60} \mathrm{Co}$ & ${ }^{137} \mathrm{Cs}$ \\
\hline & $(p \mathrm{Ci} / \mathrm{g})$ & $(\mathrm{pCi} / \mathrm{g})$ \\
\hline 2/East & $0.38 \pm 0.34$ & $35.7 \pm 1.6$ \\
\hline 2/West & $0.60 \pm 0.40$ & $104.0 \pm 3.0$ \\
\hline 3/West & $0.55 \pm 0.43$ & $41.8 \pm 2.1$ \\
\hline 4/North & $0.50 \pm 0.71$ & $144.0 \pm 5.0$ \\
\hline 4/South & $0.19 \pm 0.13$ & $4.5 \pm 0.3$ \\
\hline $8 /$ North & $0.02 \pm 0.12$ & $18.5 \pm 0.6$ \\
\hline 8/South & $0.49 \pm 0.31$ & $48.2 \pm 1.6$ \\
\hline Average & $\ldots{ }^{\mathrm{a}}$ & $\ldots \mathrm{a}$ \\
\hline
\end{tabular}


Table 2. A/R (pCi/kg/cpm) ${ }^{137} \mathrm{Cs}$ Conversion Factors for Par Pond Sediment

\begin{tabular}{|c|c|c|c|c|c|c|c|c|c|c|}
\hline \multirow{4}{*}{$\begin{array}{l}\text { Depth } \\
(\mathrm{cm})\end{array}$} & \multicolumn{5}{|c|}{$\frac{\text { Sediment at Specific Depth }}{\text { (Differential Analysis) }}$} & \multicolumn{5}{|c|}{$\frac{\text { Sediment to Specific Depth }}{\text { (Integral Analysis) }}$} \\
\hline & \multirow[t]{3}{*}{$\overline{\mathrm{P}}(\mathrm{z})$} & \multicolumn{2}{|c|}{ Density } & \multicolumn{2}{|c|}{$\mathrm{A} / \mathrm{R}$} & \multirow[t]{3}{*}{$\overline{\mathrm{P}}(\mathrm{z})$} & \multicolumn{2}{|c|}{ Density } & \multicolumn{2}{|c|}{ A/R } \\
\hline & & \multicolumn{2}{|c|}{$\left(\mathrm{g} / \mathrm{cm}^{3}\right)$} & \multicolumn{2}{|c|}{$(\mathrm{pCi} / \mathrm{kg} / \mathrm{cpm})$} & & \multicolumn{2}{|c|}{$\left(\mathrm{g} / \mathrm{cm}^{2}\right)$} & \multicolumn{2}{|c|}{$(\mathrm{pCi} / \mathrm{kg} / \mathrm{cpm})$} \\
\hline & & wet & dry & wet & $d r y$ & & wet & dry & wet & dry \\
\hline $0-1$ & 0.075 & 0.83 & 0.28 & 154 & 456 & 0.075 & 0.83 & 0.28 & 154 & 456 \\
\hline $1-2$ & 0.090 & 1.10 & 0.47 & 139 & 326 & 0.164 & 1.93 & 0.75 & 145 & 374 \\
\hline $2-3$ & 0.079 & 1.14 & 0.53 & 118 & 253 & 0.243 & 3.07 & 1.28 & 135 & 324 \\
\hline $3-4$ & 0.089 & 1.27 & 0.66 & 119 & 230 & 0.332 & 4.34 & 1.94 & 131 & 292 \\
\hline $4-5$ & 0.103 & 1.36 & 0.78 & 130 & 226 & 0.345 & 5.70 & 2.72 & 130 & 273 \\
\hline $5-6$ & 0.102 & 1.44 & 0.88 & 121 & 199 & 0.537 & 7.14 & 3.60 & 129 & 255 \\
\hline $6-7$ & 0.097 & 1.42 & 0.97 & 116 & 170 & 0.634 & 8.56 & 4.57 & 126 & 237 \\
\hline $7-8$ & 0.081 & 1.50 & 0.98 & 93 & 142 & 0.715 & 10.06 & 5.55 & 121 & 220 \\
\hline $8-9$ & 0.062 & 1.53 & 1.03 & 70 & 103 & 0.778 & 11.59 & 6.58 & 115 & 202 \\
\hline $9-10$ & 0.053 & 1.60 & 1.11 & 57 & 82 & 0.831 & 13.19 & 7.69 & 108 & 184 \\
\hline $10-11$ & 0.048 & 1.45 & 1.11 & 56 & 73 & 0.878 & 14.64 & 8.80 & 102 & 170 \\
\hline $11-12$ & 0.023 & 1.77 & 1.27 & 22 & 31 & 0.901 & 16.41 & 10.07 & 94 & 153 \\
\hline $12-13$ & 0.016 & 1.77 & 1.28 & 16 & 22 & 0.918 & 18.18 & 11.35 & 86 & 138 \\
\hline $13-14$ & 0.013 & 1.79 & 1.30 & 12 & 17 & 0.931 & 19.97 & 12.65 & 80 & 126 \\
\hline $14-15$ & 0.008 & 1.74 & 1.28 & 8 & 10 & 0.938 & 21.71 & 13.93 & 74 & 115 \\
\hline $15-16$ & 0.008 & 1.73 & 1.30 & 8 & 11 & 0.946 & 23.44 & 15.23 & 69 & 106 \\
\hline $16-17$ & 0.008 & 1.78 & 1.37 & 7 & 9 & 0.954 & 25.22 & 16.60 & 65 & 98 \\
\hline $17-18$ & 0.005 & 1.81 & 1.44 & 5 & 6 & 0.595 & 27.03 & 18.04 & 61 & 91 \\
\hline $18-19$ & 0.005 & 1.73 & 1.36 & 5 & 6 & 0.964 & 28.76 & 19.40 & 57 & 85 \\
\hline $19-20$ & 0.004 & 1.92 & 1.56 & 4 & 4 & 0.968 & 30.68 & 20.96 & 54 & 79 \\
\hline $20-21$ & 0.007 & 1.92 & 1.44 & 6 & 8 & 0.975 & 32.60 & 22.40 & 51 & 74 \\
\hline $21-22$ & 0.013 & 1.93 & 1.44 & 12 & 16 & 0.988 & 34.53 & 23.84 & 49 & 71 \\
\hline $22-23$ & 0.006 & 2.13 & 1.76 & 5 & 6 & 0.994 & 36.66 & 25.60 & 46 & 66 \\
\hline $23-24$ & 0.001 & 1.65 & 1.38 & 1 & 1 & 0.995 & 38.31 & 26.98 & 44 & 63 \\
\hline $24-25$ & 0.002 & 1.94 & 1.66 & 1 & 2 & 0.996 & 40.25 & 28.64 & 42 & 59 \\
\hline $25-26$ & 0.001 & 1.80 & 1.49 & 1 & 1 & 0.998 & 42.05 & 30.13 & 41 & 57 \\
\hline $26-27$ & 0.001 & 1.76 & 1.55 & 1 & 1 & 0.998 & 43.81 & 31.68 & 39 & 54 \\
\hline $27-28$ & 0.000 & 1.82 & 1.62 & & & 0.998 & 45.63 & 33.30 & 37 & 51 \\
\hline $28-29$ & 0.000 & 2.02 & 1.79 & & & 0.999 & 47.65 & 35.09 & 36 & 49 \\
\hline $29-30$ & 0.000 & 2.05 & 1.85 & & & 0.999 & 49.70 & 36.94 & 34 & 46 \\
\hline $30-31$ & 0.000 & 1.82 & 1.63 & & & 0.999 & 51.52 & 38.57 & 33 & 44 \\
\hline $31-32$ & 0.000 & 1.89 & 1.69 & & & 0.999 & 53.41 & 40.26 & 32 & 42 \\
\hline $32-33$ & 0.000 & 1.91 & 1.68 & & & 0.999 & 55.32 & 41.94 & 31 & 41 \\
\hline $33-34$ & 0.000 & 1.77 & 1.70 & & & 0.999 & 57.09 & 43.64 & 30 & 39 \\
\hline $34-35$ & 0.000 & 1.82 & 1.76 & & & 1.000 & 58.91 & 45.40 & 29 & 38 \\
\hline $35-36$ & 0.000 & 2.01 & 1.94 & & & 1.000 & 60.92 & 47.34 & 28 & 36 \\
\hline $36-37$ & 0.000 & 2.06 & 1.98 & & & 1.000 & 62.98 & 49.32 & 27 & 35 \\
\hline $37-38$ & 0.000 & 1.82 & 1.76 & & & 1.000 & 64.80 & 51.08 & 26 & 33 \\
\hline
\end{tabular}

Note: average profiles for density and and $\mathrm{P}(\mathrm{z})$ from data provided by F.C. Whicker et al, SREL (ref 4) 
Table 3. Par Pond ${ }^{137} \mathrm{Cs}$ Inventory Analysis

\begin{tabular}{|c|c|c|c|c|c|}
\hline \multicolumn{2}{|c|}{ Depth Range } & \multirow{2}{*}{$\frac{\text { Area }^{\mathrm{a}}}{{\text { (hectare })^{\mathrm{b}}}^{-}}$} & \multicolumn{3}{|c|}{${ }^{137} \mathrm{Cs}$} \\
\hline (m) & (ft) & & (avg cpm) & $(\mathrm{Ci})^{\mathrm{c}}$ & (Accum $\mathrm{Ci})$ \\
\hline $0-3$ & $0.0-9.8$ & 317.29 & 60.8 & 3.29 & 3.29 \\
\hline $3-6$ & $9.8-19.7$ & 226.66 & 169.6 & 6.57 & 9.86 \\
\hline $6-9$ & $19.7-29.5$ & 219.52 & 387.7 & 14.53 & 24.39 \\
\hline $9-12$ & $29.5-39.4$ & 166.78 & 395.1 & 11.30 & 35.70 \\
\hline $12-15$ & $39.4-49.2$ & 85.15 & 436.8 & 7.19 & 42.84 \\
\hline $15-18$ & $49.2-59.1$ & 41.11 & 534.2 & 4.59 & 46.59 \\
\hline
\end{tabular}

a Data from J.E. Pinder, SREL.

$b$ hectare $=10^{4} \mathrm{~m}^{2}$

c $A R=0.0171 \pm 0.0027 \mu \mathrm{Ci} / \mathrm{m}^{2} / \mathrm{cpm}$

Estimated Cases for ${ }^{137} \mathrm{Cs}$ in Sediment

(Errors dominated by A/R error)

Case

Sediment exposed in drawdown to $181 \mathrm{ft} \mathrm{msl}$

Sediment inventory of entire pond
Depth Range

(ft)

$0.0-19.0$

$0.0-59.1$

$46.59 \pm 7.24$ 
Table 4. Comparison of ${ }^{137} \mathrm{Cs}$ Estimates for Sediments of Lower Three Runs System

\section{Location}

\section{Pond B}

Pond C

Par Pond

Lower Three Runs Areas

Total

History

\section{0}

-

$-$

$-$

83.0*

${ }^{137}$ Cs Estimates for Sediments ${ }^{a}$

\section{Prediction $^{\mathrm{b}}$}

$$
12.0
$$

$2-7$

35-59

5-34

83.0
Cs Report ${ }^{c}$

SREL

$12.0^{*}$

$\underline{-3.5}$

$\sim 44.0$

23.5

25.8

83.0
Present

12.0

46.6

20.5

83.0

\footnotetext{
anderlined entries are based on pond measurements; the " $"$ " denotes preliminary estimates based on pond measurements. Other entries depend on historical data. For entries with identical values, the one denoted "*" identifies the estimate from which it originated.

b The predicted ranges result as follows: due to its large area Par Pond is estimated to contain at least $35 \mathrm{Ci}$ of a possible $71 \mathrm{Ci}$; however, Pond $\mathrm{C}$ and Lower Three Runs are estimated to have at least as much as the $12 \mathrm{Ci}$ of Pond $\mathrm{B}$, so that the upper limit for Par Pond is $59 \mathrm{Ci}$. Assuming, Pond $\mathrm{C}$ is similar to Par Pond, it would have at least $2 \mathrm{Ci}$ based on pond area ratios; if similar to Pond B, a value of $12 \mathrm{Ci}$ is estimated. However, because Pond $C$ is closer to $P a r$ Pond than Pond $C$, the average a value of $(12+2) / 2=7 \mathrm{Ci}$ is given as an upper limit. If $7 \mathrm{Ci}$ were in $\mathrm{Pond} \mathrm{C}$, the minimum in Lower Three Runs is calculated as $71-59-7=5 \mathrm{Ci}$; similarly, the maximum is calculated as $71-35 \cdot 2=34 \mathrm{Ci}$.

c See reference 1 .
} 


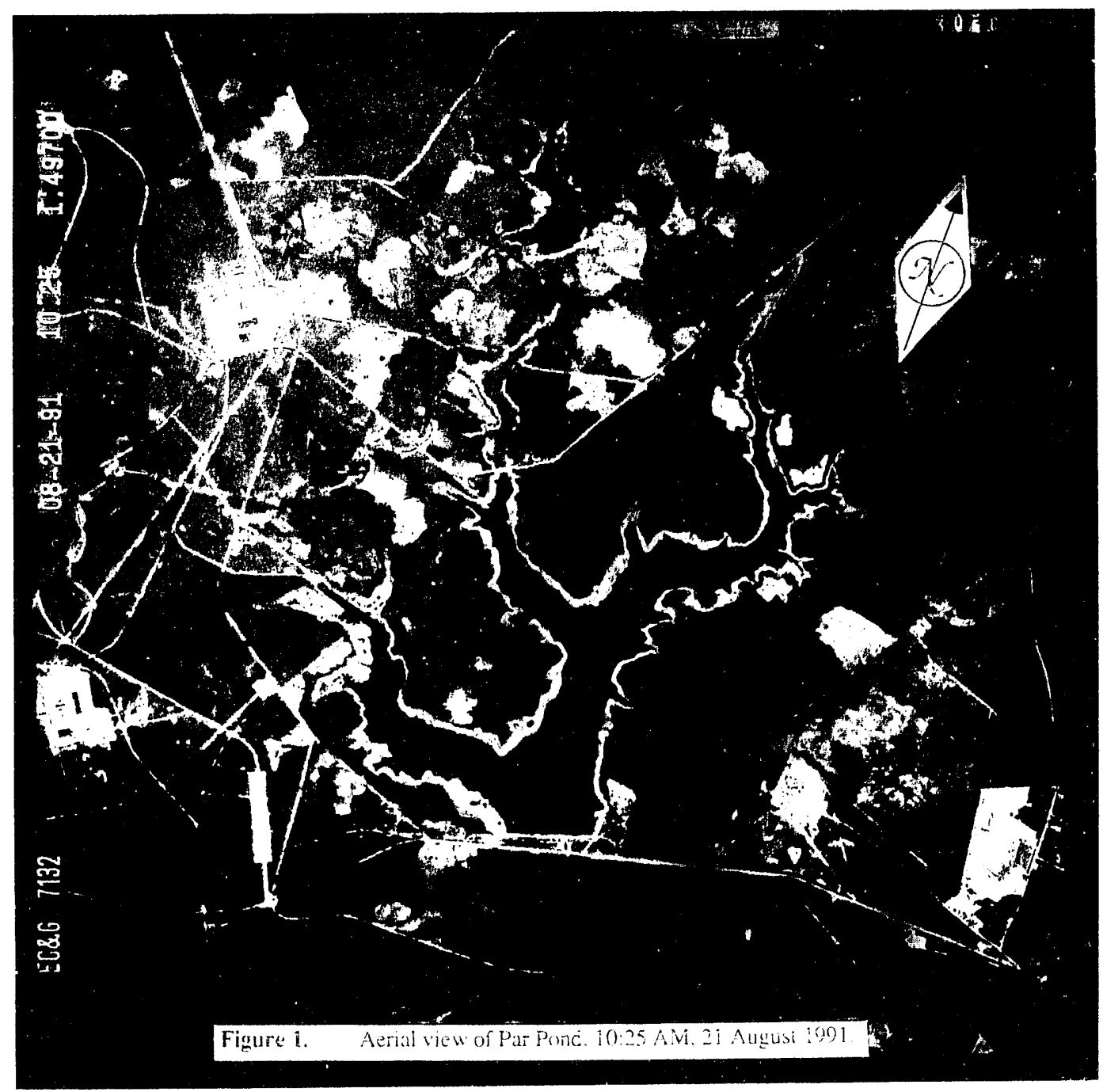




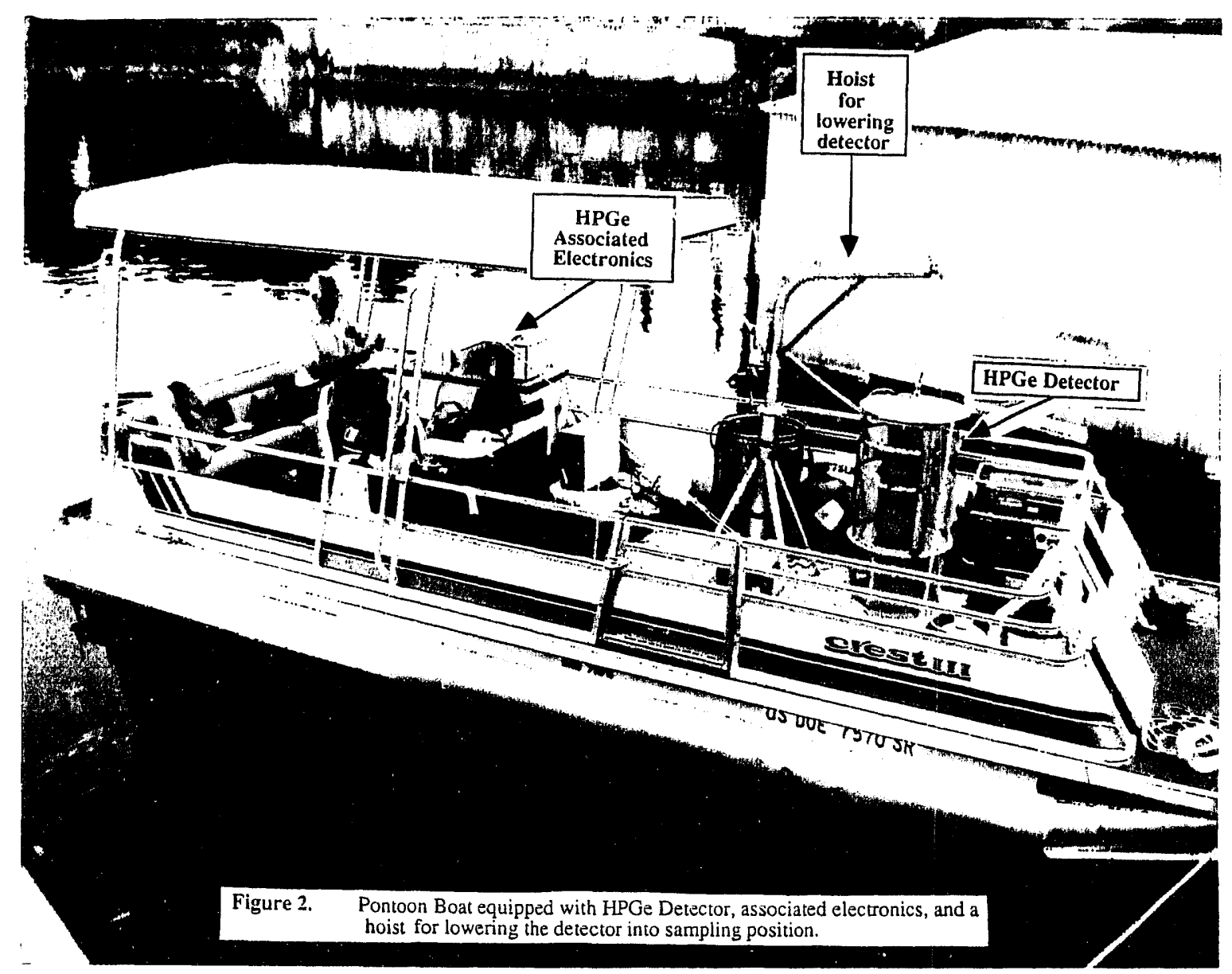




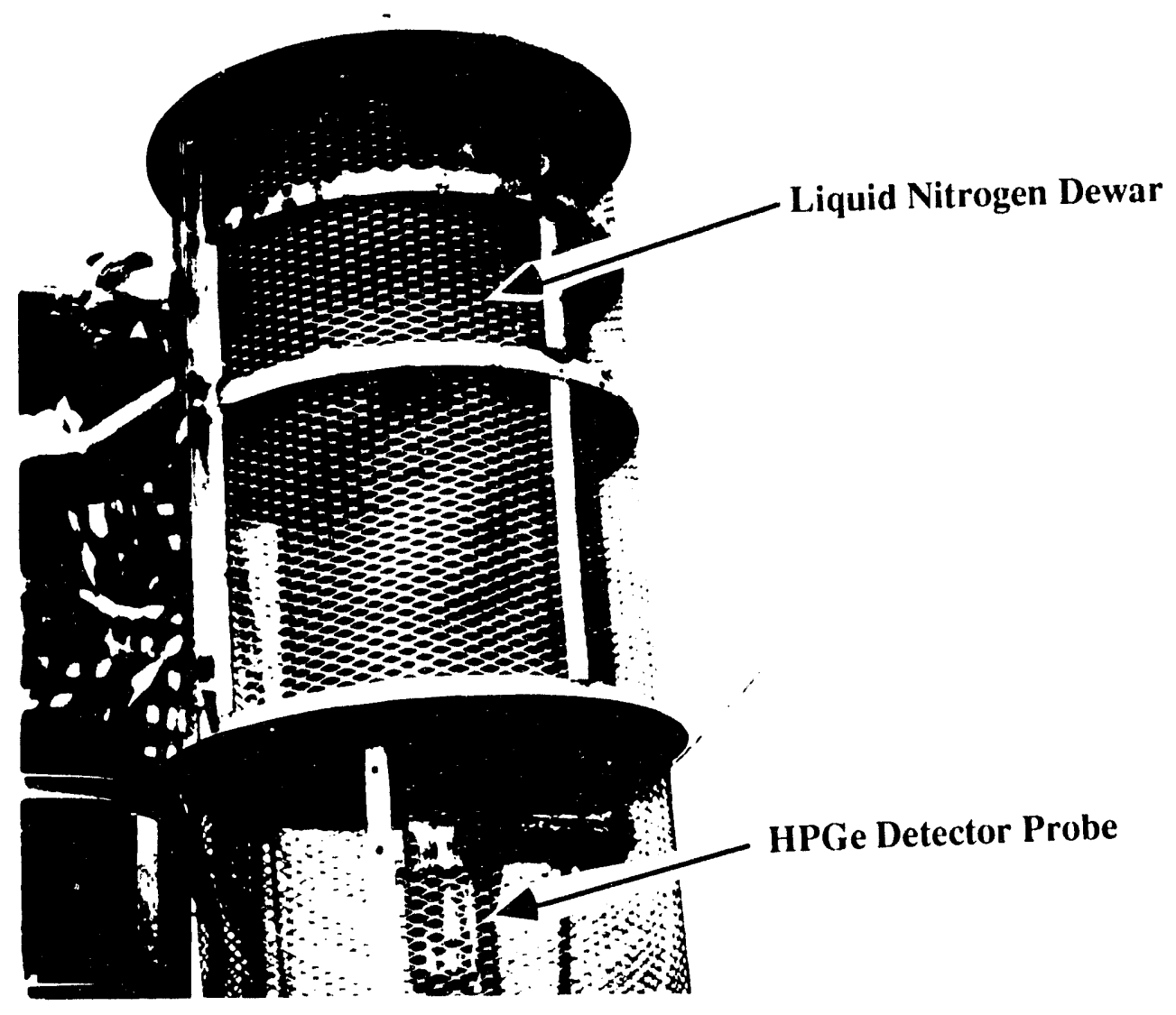

Figure 3. Detector assembly unit with HPGe Detector Probe and Liquid Nitrogen Dewar. 


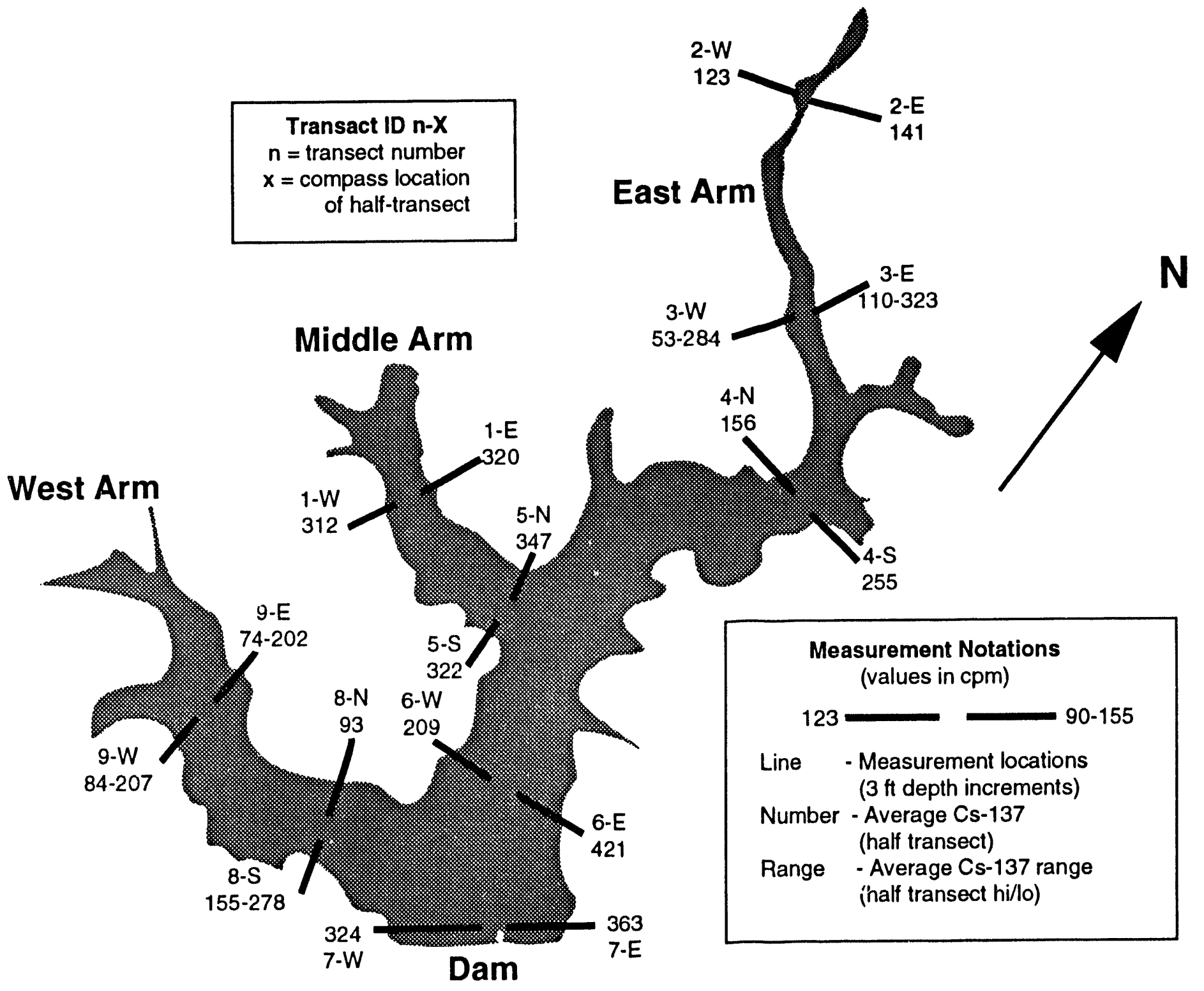

93X1494.15.AIL

Figure 4. Measurement of ${ }^{137} \mathrm{Cs}$ Countrate for Transects. 

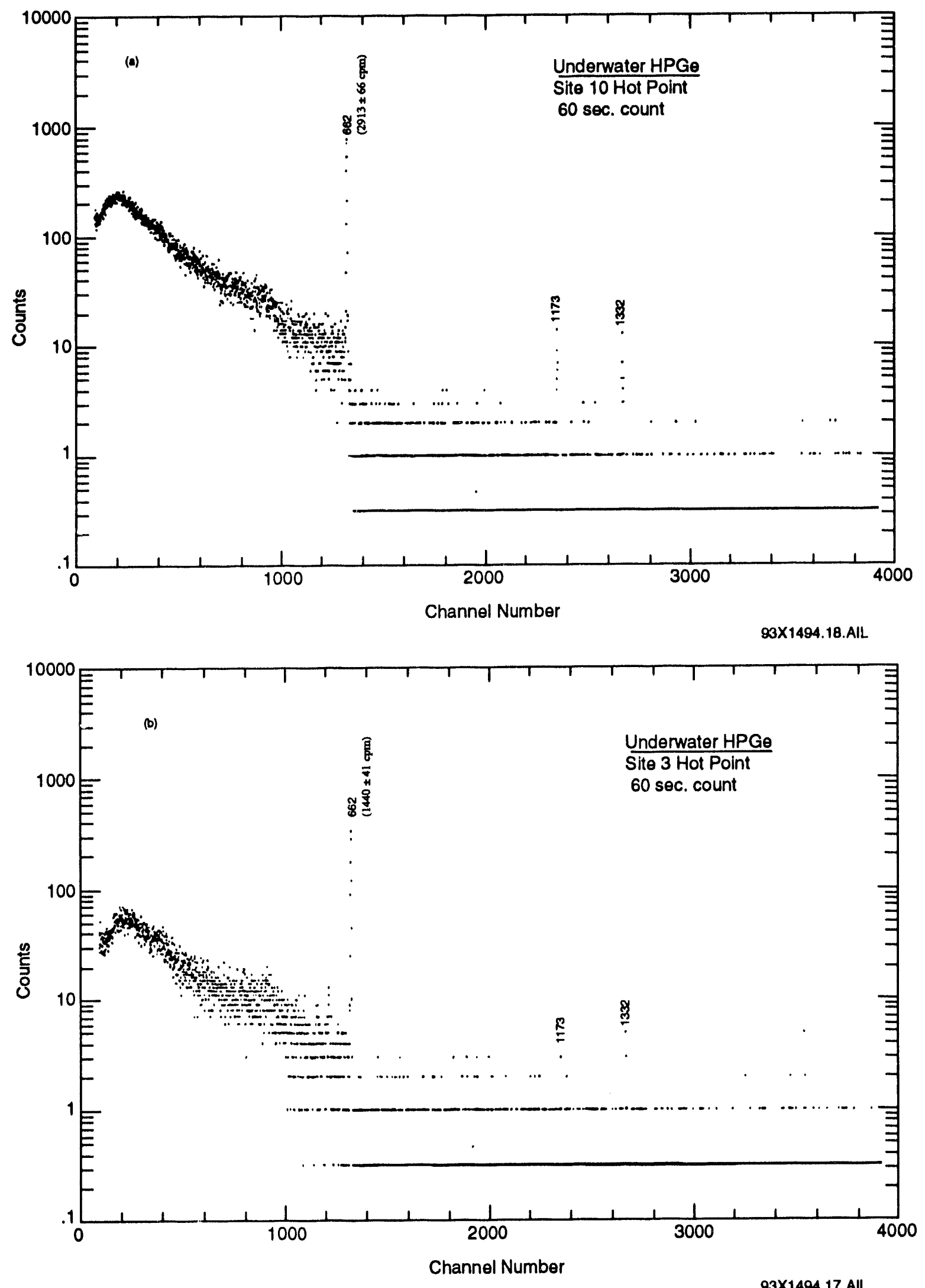

Flgure 5. Underwater HPGe Gamma Spectra of Sediment Measured for (a) Hottest Point In the Pond and (b) Hottest Point in the Uncovered Sediment. 

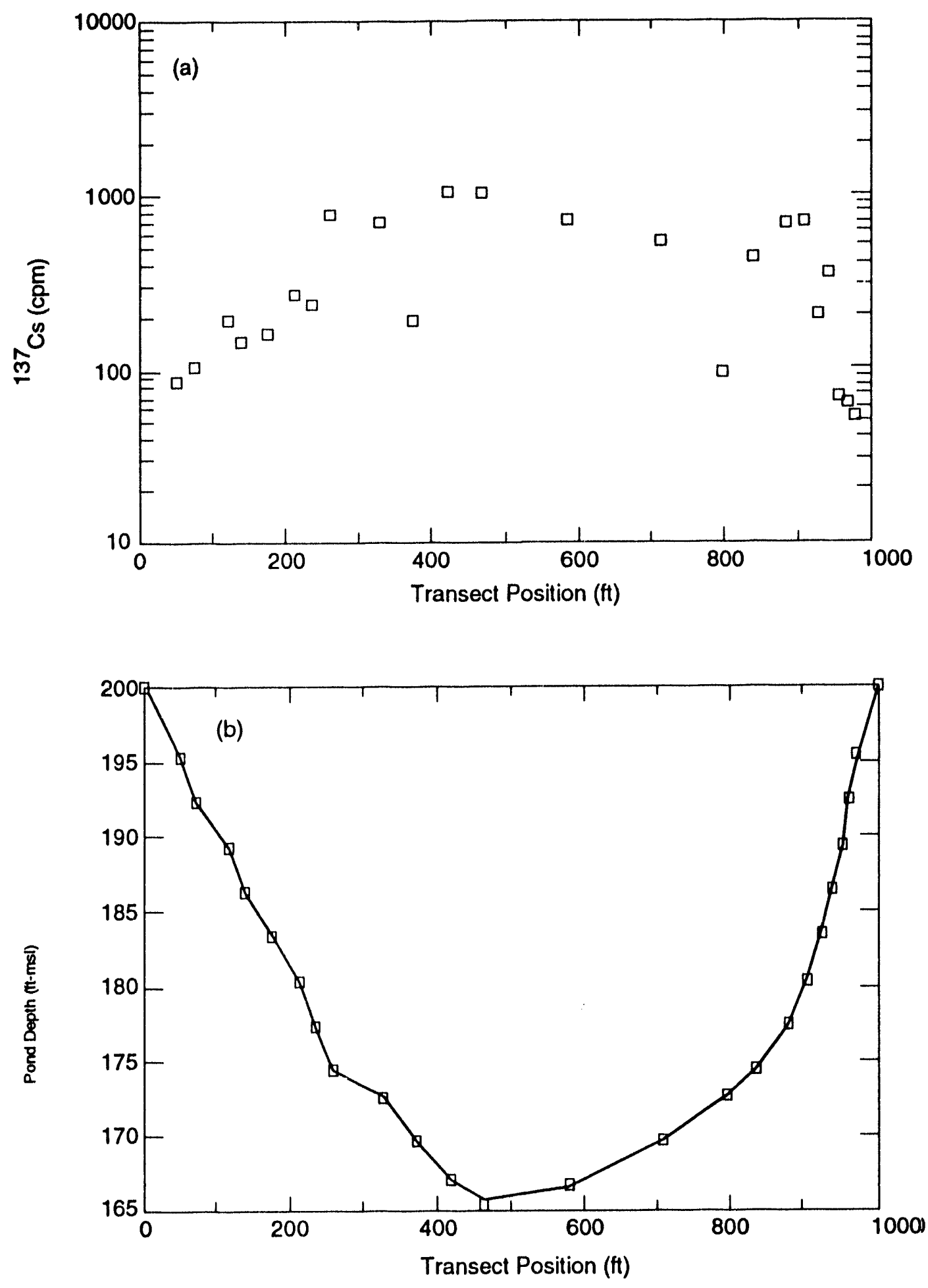

M93X1494.05.AlL

Figure 6. Transect 1 Measurements of (a) ${ }^{137} \mathrm{Cs}$ and (b) Pond Depth. 


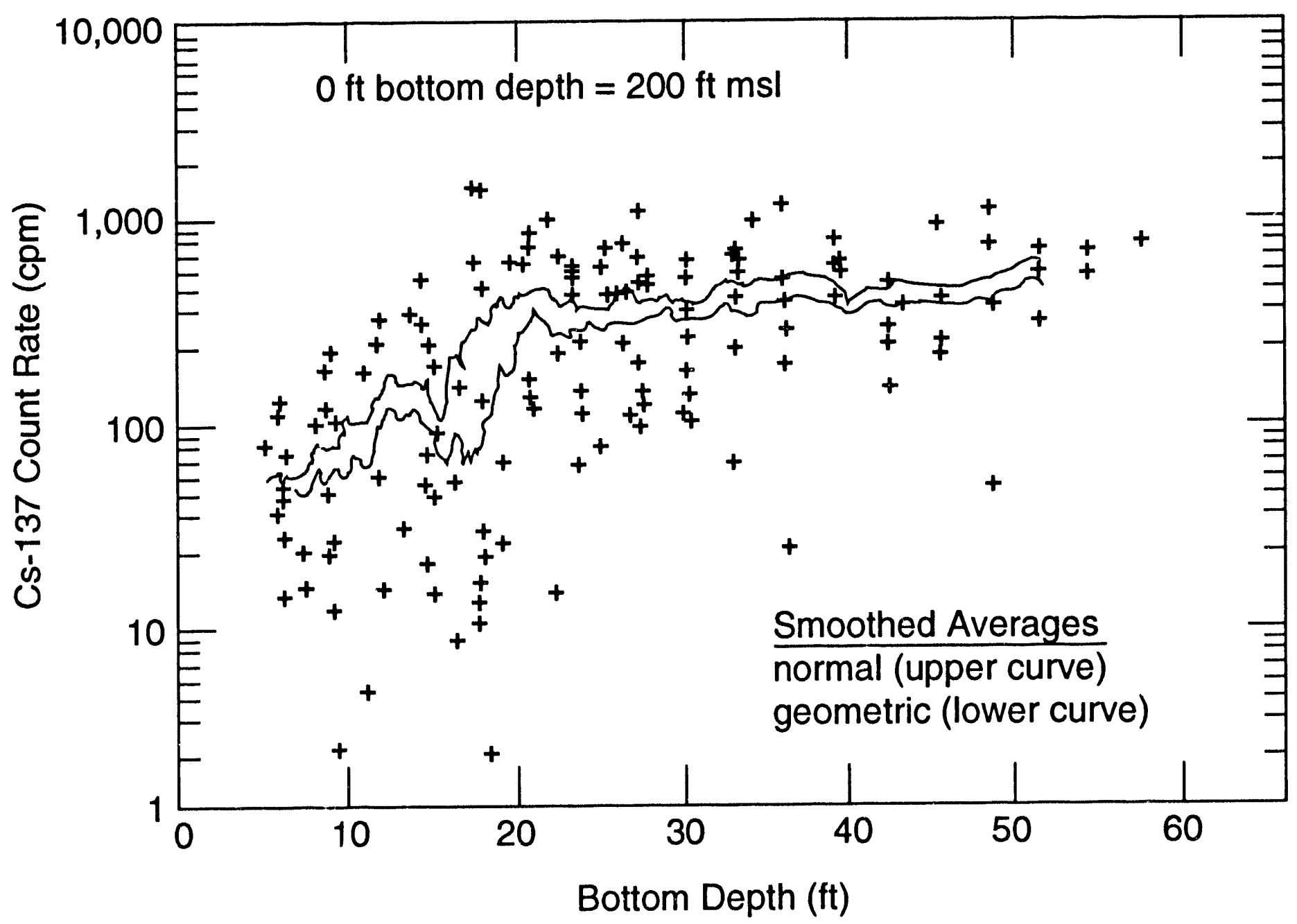

$93 \times 1494.16$. AlL

Figure 7. ${ }^{137} \mathrm{Cs}$ Measurements for Transects 1-9 and their Smoothed Averages as a Function of Pond Depth. 

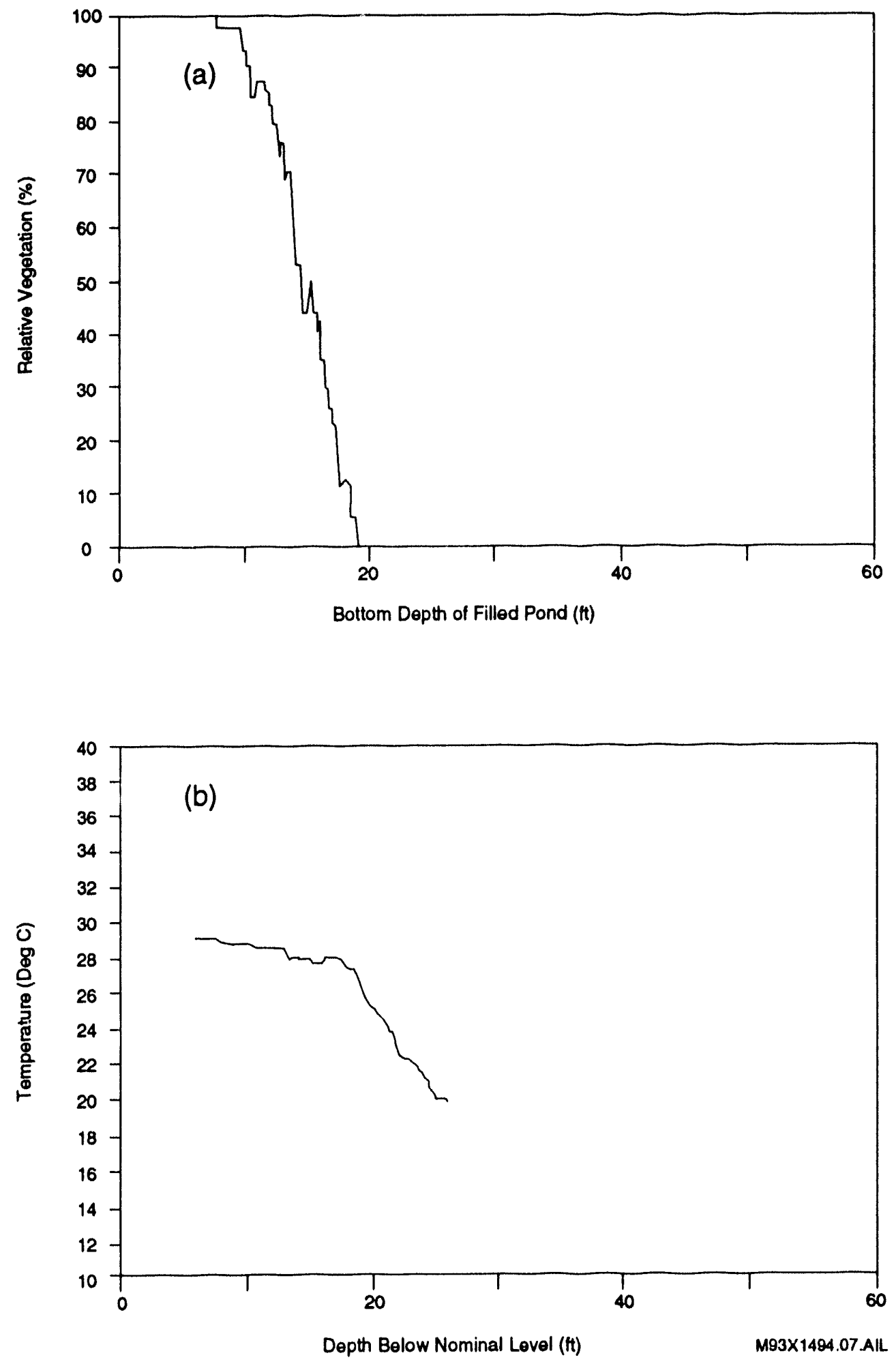

Figure 8. Smoothed Averages of (a) Vegetation and (b) Sediment Temperature as Function of Pond Depth. 


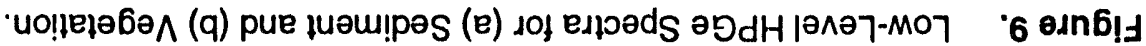
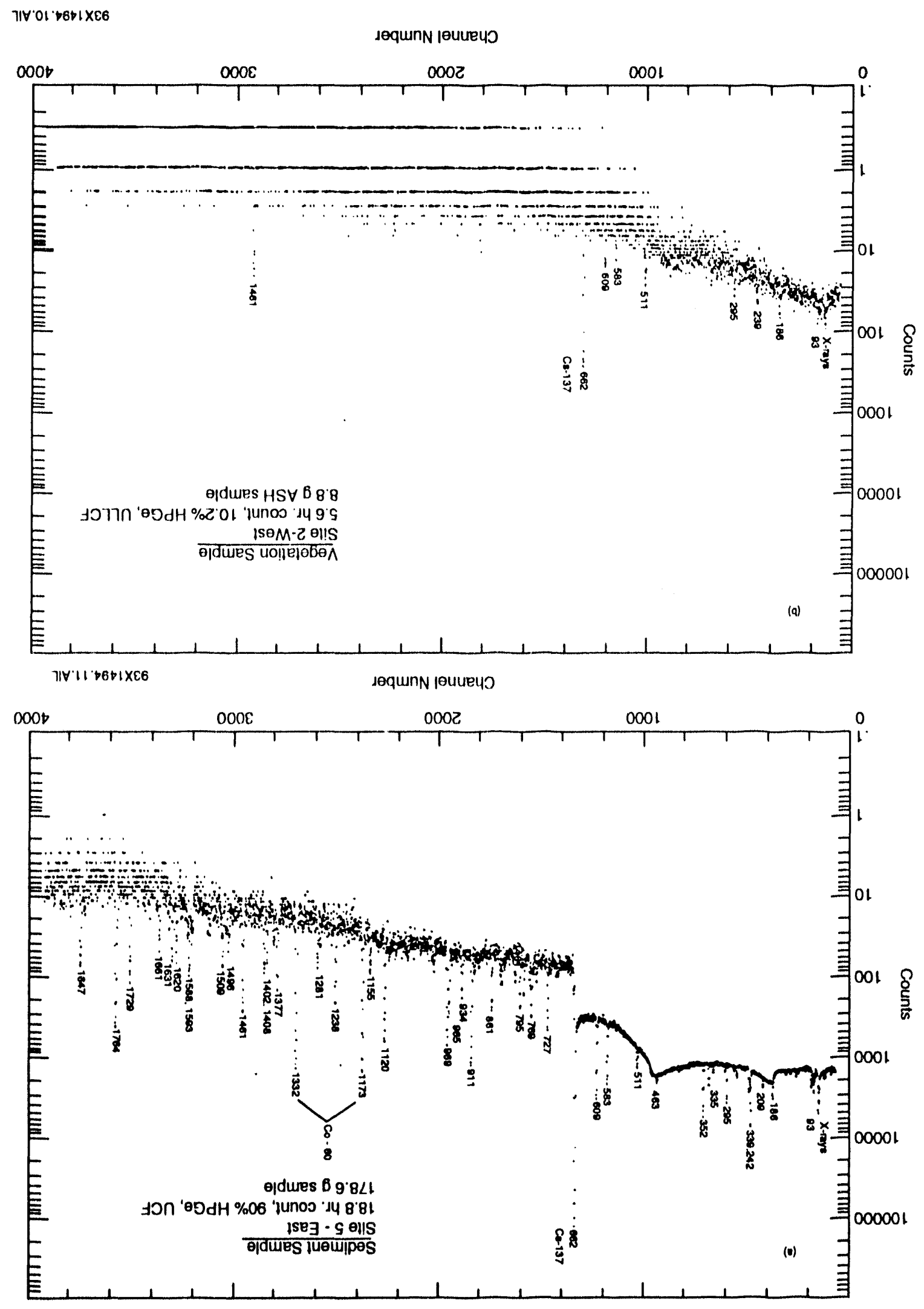


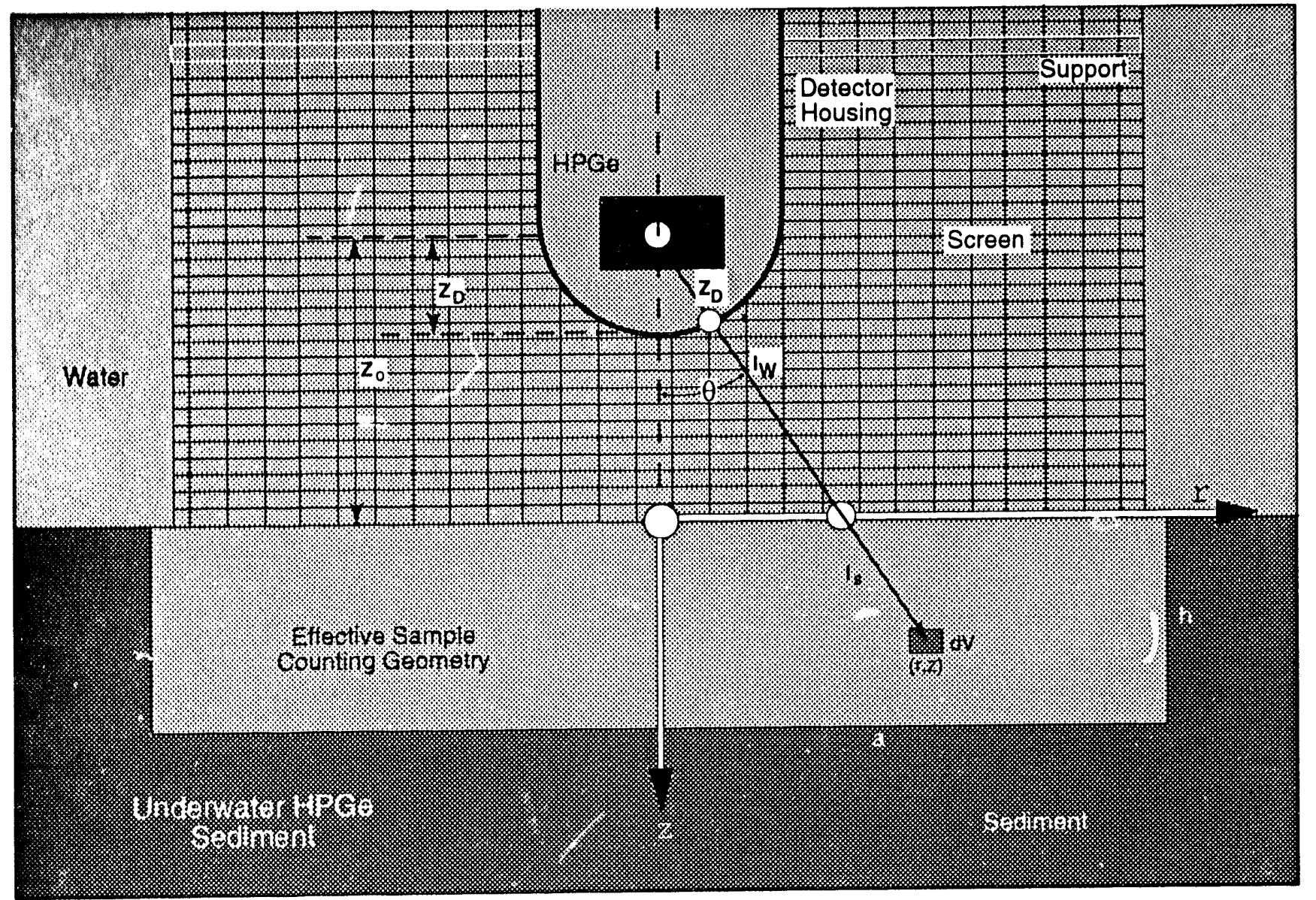

93X1494.06.All

Figure 10. Geometry and Parameters Used in Detector Efficiency Calculational Model 

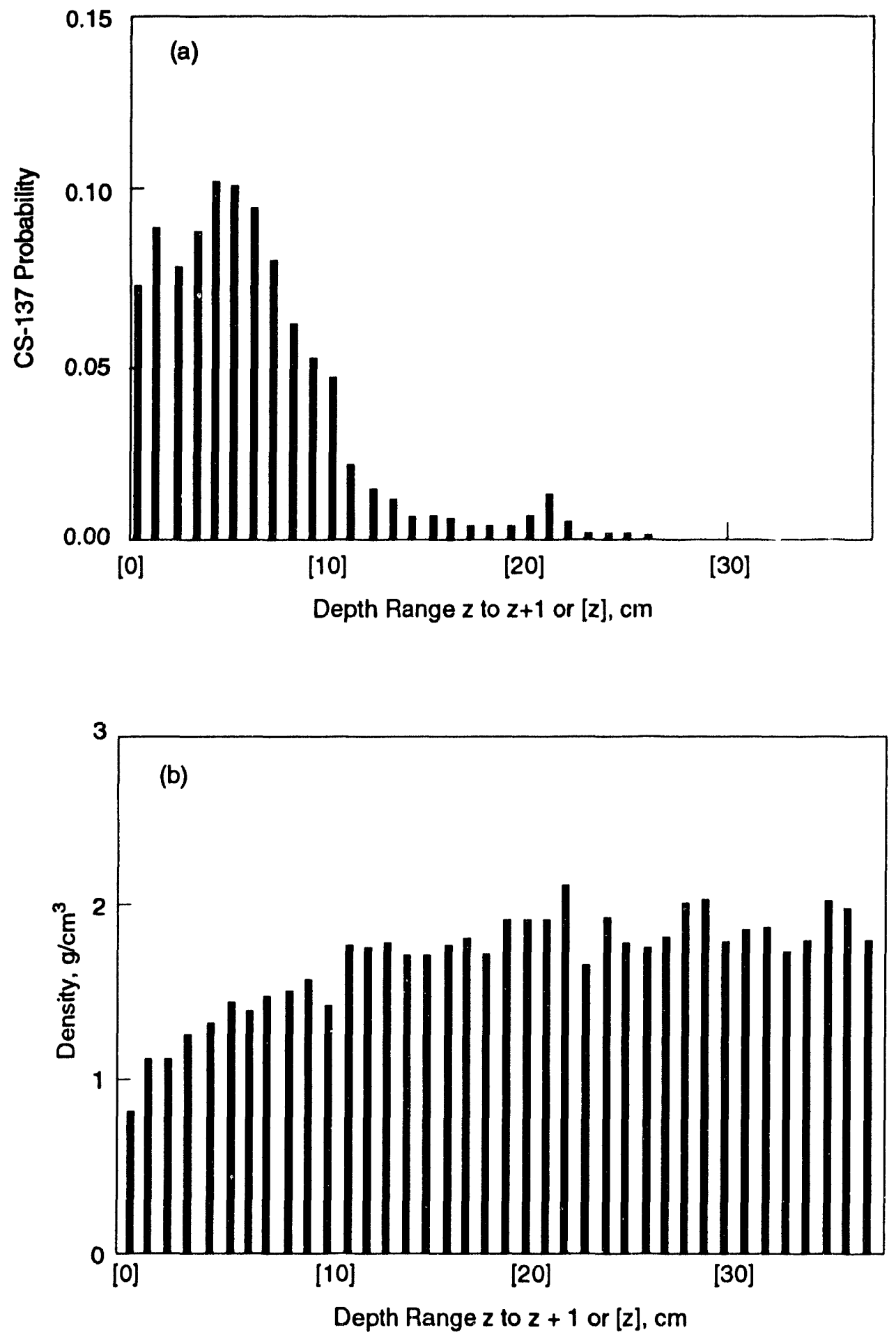

M93X1494.08.AIL

Figure 11. Average Sediment Depth Dependence of (a) ${ }^{137}$ Cs Probability and (b) Sediment Density. 


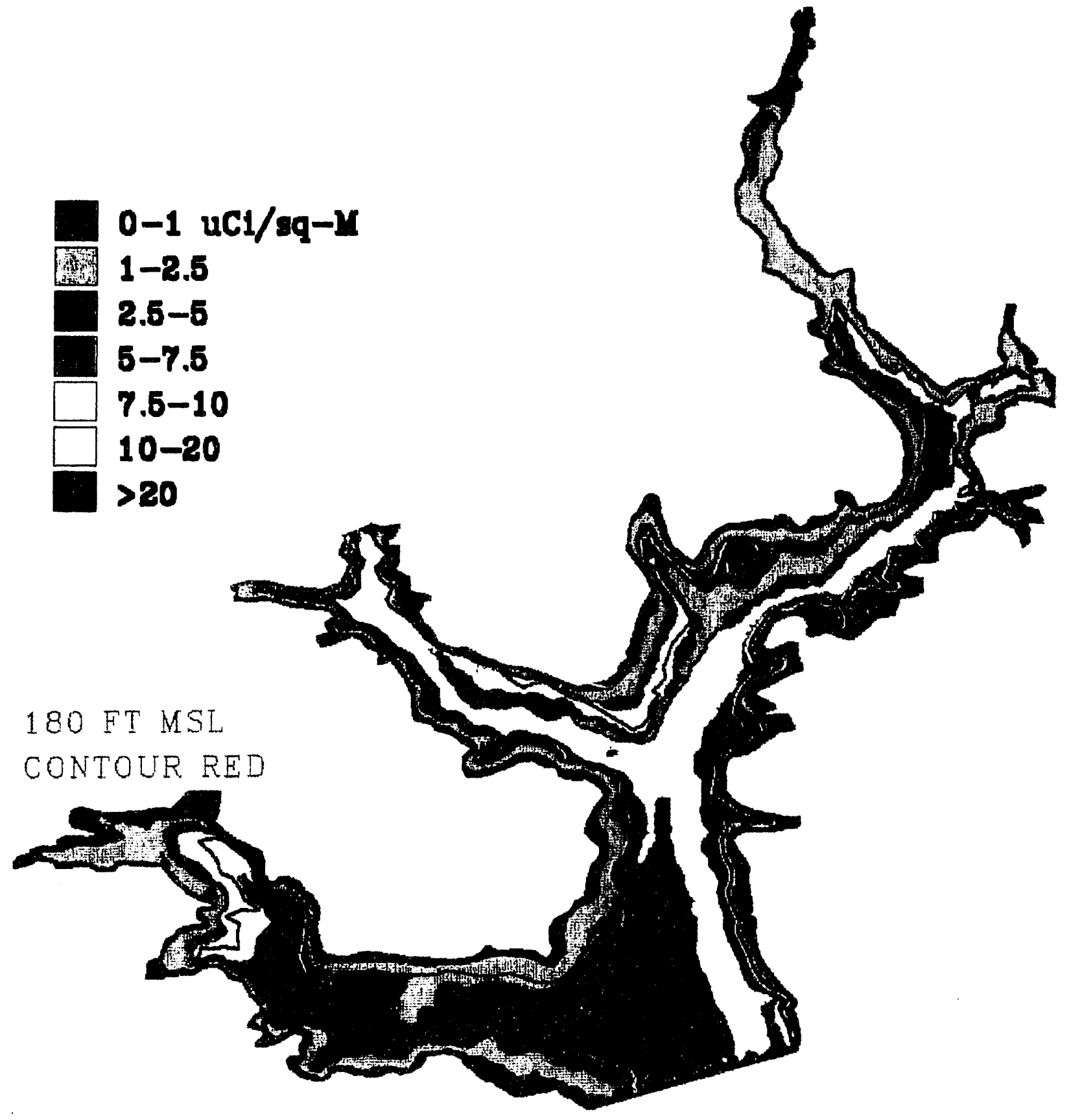

Figure 12. Contour Map of ${ }^{137} \mathrm{Cs}$ Distribution in Par Pond. 


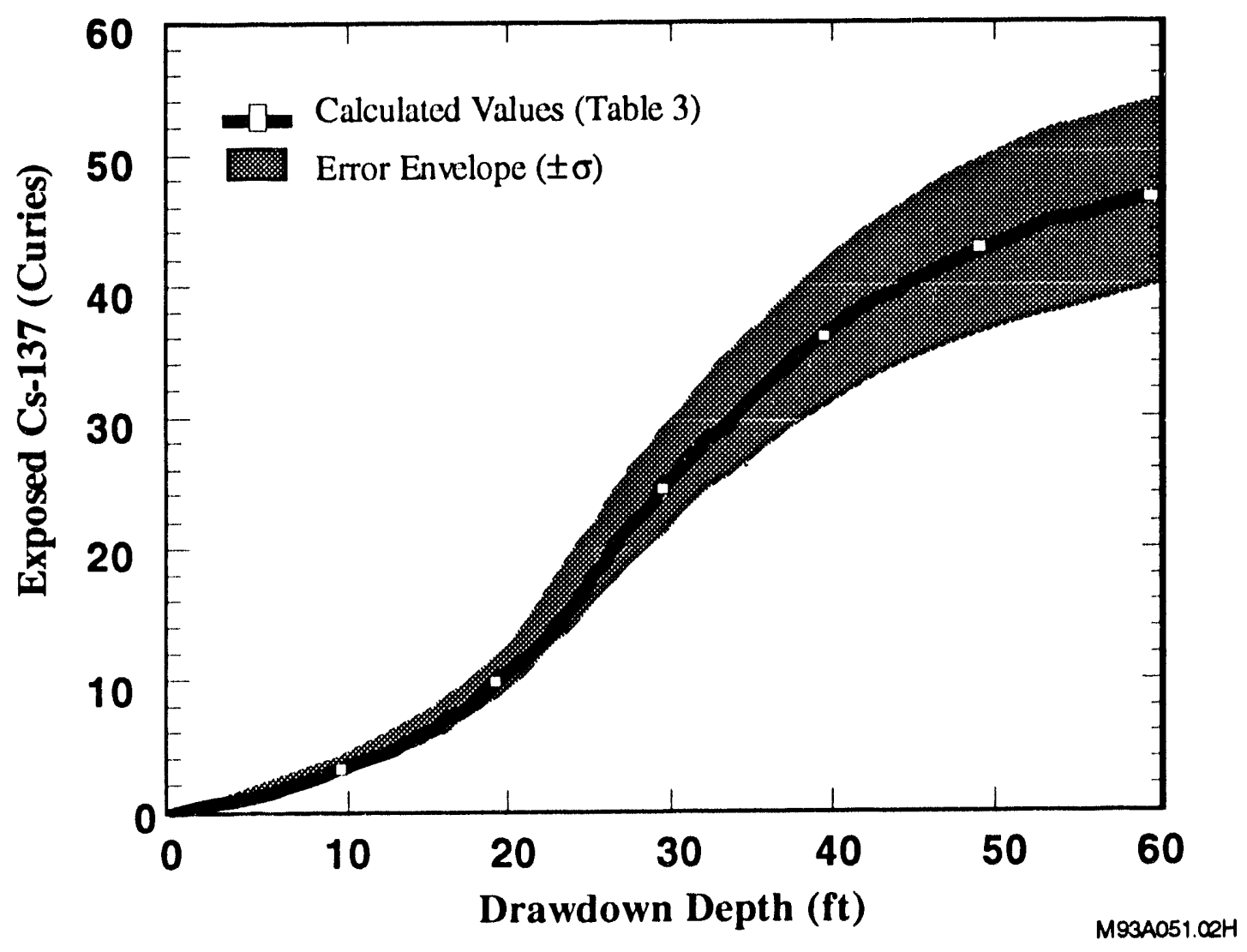

Figure 13. ${ }^{137} \mathrm{Cs}$ in Sediment exposed as a function of drawdown depth (see Table 3). 


\section{Appendix A. Raw Data - Underwater HPGe Measurements}

The raw data for the underwater HPGe measurements of Par Pond are summarized in Table A.1. Following the notations of Figure 4, all data are categorized according to their transects, and corresponding half-transects are identified according to the general compass directions of their associated shores.

The table gives the position coordinates of each measurement in terms of latitude, longitude, and pond depth. The latitudes and longitudes are approximate, as they are primarily based on visualization of landmarks that could be identified from maps. However, a Magellan GPS unit was available to benchmark some of positions, including those associated with characterizing the "hot spot" of transect \#10. The general positioning is estimated to be $\pm 0.03 \mathrm{~min}$ $( \pm 50 \mathrm{~m})$ for both latitude and longitude; however, relative positions along a given transect could be pin-pointed to about $\pm 0.01 \mathrm{~min}( \pm 15$ $\mathrm{m})$ using the pond depth measurements and contour maps, as was done in generating the ${ }^{137} \mathrm{Cs}$ map of Figure 12. The table gives the depths in units of feet relative to mean sea level or "ft msl". Par Pond at full pool is at $200 \mathrm{ft} \mathrm{msl}$; thus, actual pond depths at full pool are $200 \mathrm{ft}$ minus the tabulated depth.
The underwater HPGe count rate of the $662 \mathrm{keV}$ gamma peak of ${ }^{137} \mathrm{Cs}$ is that observed in one minute of counting. The counting dates for the data range from $7 / 11 / 91$ to $11 / 5 / 91$, which is 117 days; thus, the mid-date of $9 / 8 / 91$ for this range is within \pm 59 days of all measurement dates. Relative to $9 / 8 / 91$, all the data corrections for ${ }^{137} \mathrm{Cs}$ decay are within $\pm 0.4 \%$, which was negligible relative to other errors of the study. Accordingly, the tabulated count rates are not corrected for decay, and a reference date of 9/8/91 is reasonable for comparisons with other ${ }^{137} \mathrm{Cs}$ observations that correspond to significantly remoter dates.

Temperature and vegetation measurements at the bottom depths were taken during the July measurements, before significant drawdown had occurred. These measurements were made for transects 2-9. The tabulated temperatures are self explanatory. For the vegetation observations, a " $Y$ " indicates positive evidence for bottom vegetation, a "Y/N" denotes borderline evidence, and an " $\mathrm{N}$ " means no vegetation. The presence of vegetation was determined by visual observation and/or by the patterns on the Lowrance depth finder. 
Table A.1. Raw Data - Underwater HPGe Measurements

\begin{tabular}{|c|c|c|c|c|c|c|c|}
\hline Transect & Lat $81 \mathrm{~N}$ & Lon $33 \mathrm{~W}$ & Depth & Countrate & Temp & Veg & Data Date \\
\hline & $(\min )$ & $(\min )$ & (ft msl) & (cpm) & $(\operatorname{deg} C)$ & & \\
\hline 1 & 15.64 & 32.34 & 195.3 & $73 \pm 9$ & & & $7 / 11 / 91$ \\
\hline \multirow[t]{11}{*}{ West } & 15.65 & 32.34 & 192.3 & $89 \pm 9$ & & & $7 / 11 / 91$ \\
\hline & 15.66 & 32.33 & 189.3 & $167 \pm 13$ & & & $7 / 11 / 91$ \\
\hline & 15.66 & 32.33 & 186.3 & $125 \pm 11$ & & & $7 / 11 / 91$ \\
\hline & 15.67 & 32.32 & 183.3 & $140 \pm 12$ & & & $7 / 11 / 91$ \\
\hline & 15.68 & 32.32 & 180.3 & $233 \pm 19$ & & & $7 / 11 / 91$ \\
\hline & 15.68 & 32.31 & 177.3 & $208 \pm 15$ & & & $7 / 11 / 91$ \\
\hline & 15.69 & 32.31 & 174.3 & $683 \pm 29$ & & & $7 / 11 / 91$ \\
\hline & 15.70 & 32.30 & 172.5 & $622 \pm 33$ & & & $9 / 19 / 91$ \\
\hline & 15.70 & 32.30 & 169.5 & $164 \pm 27$ & & & $9 / 19 / 91$ \\
\hline & 15.71 & 32.29 & 167.0 & $943 \pm 30$ & & & $10 / 01 / 91$ \\
\hline & 15.71 & 32.29 & 165.5 & $930 \pm 48$ & & & $9 / 19 / 91$ \\
\hline 1 & 15.71 & 32.28 & 166.5 & $640 \pm 27$ & & & 9/19/91 \\
\hline \multirow{11}{*}{ East } & 15.72 & 32.27 & 169.5 & $489 \pm 33$ & & & $9 / 19 / 91$ \\
\hline & 15.72 & 32.26 & 172.5 & $84 \pm 14$ & & & $9 / 19 / 91$ \\
\hline & 15.72 & 32.26 & 174.3 & $390 \pm 21$ & & & $7 / 11 / 91$ \\
\hline & 15.72 & 32.26 & 177.3 & $615 \pm 29$ & & & $7 / 11 / 91$ \\
\hline & 15.72 & 32.26 & 180.3 & $632 \pm 27$ & & & $7 / 11 / 91$ \\
\hline & 15.73 & 32.25 & 183.3 & $181 \pm 18$ & & & $7 / 11 / 91$ \\
\hline & 15.73 & 32.25 & 186.3 & $315 \pm 22$ & & & $7 / 11 / 91$ \\
\hline & 15.74 & 32.24 & 189.3 & $63 \pm 18$ & & & $7 / 11 / 91$ \\
\hline & 15.74 & 32.24 & 189.3 & $4 \pm 2$ & & & $7 / 11 / 91$ \\
\hline & 15.74 & 32.24 & 192.3 & $57 \pm 8$ & & & $7 / 11 / 91$ \\
\hline & 15.74 & 32.23 & 195.3 & $48 \pm 10$ & & & $7 / 11 / 91$ \\
\hline 2 & 17.62 & 31.15 & 194.3 & $44 \pm 10$ & 28.3 & $\mathrm{Y}$ & $7 / 17 / 91$ \\
\hline \multirow[t]{3}{*}{ West } & 17.62 & 31.15 & 191.3 & $166 \pm 13$ & 28.3 & $Y$ & $7 / 17 / 91$ \\
\hline & 17.62 & 31.13 & 188.3 & $239 \pm 19$ & 28.0 & $Y$ & $7 / 17 / 91$ \\
\hline & 17.62 & 31.12 & 185.3 & $44 \pm 17$ & 26.6 & $\mathrm{Y} / \mathrm{N}$ & $7 / 17 / 91$ \\
\hline 2 & 17.62 & 31.11 & 185.3 & $126 \pm 16$ & 23.3 & $\mathbf{N}$ & $7 / 17 / 91$ \\
\hline \multirow[t]{4}{*}{ East } & 17.62 & 31.11 & 185.3 & $136 \pm 12$ & 23.3 & $\mathbf{N}$ & $7 / 17 / 91$ \\
\hline & 17.62 & 31.10 & 188.3 & $234 \pm 21$ & 26.5 & $\mathbf{Y} / \mathbf{N}$ & $7 / 17 / 91$ \\
\hline & 17.62 & 31.08 & 191.3 & $73 \pm 9$ & 28.1 & $\mathbf{Y}$ & $7 / 17 / 91$ \\
\hline & 17.62 & 31.08 & 194.3 & $119 \pm 16$ & 28.2 & $\mathrm{Y}$ & $7 / 17 / 91$ \\
\hline 3 & 16.87 & 30.86 & 194.3 & $40 \pm 6$ & 29.0 & $\mathrm{Y}$ & $7 / 17 / 91$ \\
\hline \multirow[t]{5}{*}{ West } & 16.87 & 30.85 & 191.3 & $10 \pm 3$ & 29.1 & $\mathrm{Y}$ & $7 / 17 / 91$ \\
\hline & 16.87 & 30.84 & 188.3 & $47 \pm 7$ & 28.8 & $\mathrm{Y} / \mathrm{N}$ & $7 / 17 / 91$ \\
\hline & 16.88 & 30.84 & 185.3 & $17 \pm 5$ & 28.7 & $\mathbf{N}$ & $7 / 17 / 91$ \\
\hline & 16.88 & 30.83 & 182.3 & $1440 \pm 41$ & 28.5 & $\mathbf{N}$ & $7 / 17 / 91$ \\
\hline & 16.89 & 30.80 & 179.3 & $152 \pm 17$ & 26.4 & $\mathbf{N}$ & $7 / 17 / 91$ \\
\hline
\end{tabular}


Table A.1. (Continued)

\begin{tabular}{|c|c|c|c|c|c|c|c|}
\hline Transect & Lat $81 \mathrm{~N}$ & Lon $33 W$ & Depth & Countrate & Temp & Veg & Data Date \\
\hline & (min) & $(\min )$ & (ft msl) & (cpm) & $(\operatorname{deg} C)$ & & \\
\hline 3 & 16.90 & 30.79 & 179.0 & $272 \pm 18$ & 27.6 & $\mathbf{N}$ & $7 / 18 / 91$ \\
\hline \multirow[t]{5}{*}{ East } & 16.91 & 30.77 & 182.0 & $1388 \pm 40$ & 27.2 & $\mathbf{N}$ & $7 / 18 / 91$ \\
\hline & 16.91 & 30.76 & 185.0 & $12 \pm 4$ & 28.1 & $Y$ & $7 / 18 / 91$ \\
\hline & 16.92 & 30.76 & 188.0 & $117 \pm 13$ & 28.2 & $\mathrm{Y}$ & $7 / 18 / 91$ \\
\hline & 16.92 & 30.75 & 191.0 & $93 \pm 11$ & 28.9 & $\mathbf{Y}$ & $7 / 18 / 91$ \\
\hline & 16.92 & 30.74 & 194.0 & $57 \pm 9$ & 28.7 & $\mathbf{Y}$ & $7 / 18 / 91$ \\
\hline \multirow{11}{*}{$\begin{array}{c}4 \\
\text { North }\end{array}$} & 16.27 & 30.60 & 194.5 & $12 \pm 5$ & 29.8 & $\mathbf{Y}$ & $7 / 16 / 91$ \\
\hline & 16.27 & 30.59 & 191.5 & $41 \pm 7$ & 29.8 & $\mathbf{Y}$ & $7 / 16 / 91$ \\
\hline & 16.26 & 30.59 & 188.5 & $106 \pm 11$ & 29.3 & $\mathbf{Y}$ & $7 / 16 / 91$ \\
\hline & 16.26 & 30.59 & 185.5 & $17 \pm 8$ & 29.7 & $\mathrm{Y}$ & $7 / 16 / 91$ \\
\hline & 16.25 & 30.58 & 182.5 & $14 \pm 3$ & 29.5 & $\mathrm{Y}$ & $7 / 16 / 91$ \\
\hline & 16.25 & 30.58 & 182.5 & $9 \pm 4$ & 26.7 & $Y$ & $7 / 16 / 91$ \\
\hline & 16.25 & 30.58 & 179.5 & $259 \pm 16$ & 24.8 & $\mathbf{N}$ & $7 / 16 / 91$ \\
\hline & 16.25 & 30.58 & 176.5 & $498 \pm 29$ & 19.3 & $\mathbf{N}$ & $7 / 16 / 91$ \\
\hline & 16.25 & 30.57 & 173.5 & $409 \pm 25$ & 19.7 & $\mathbf{N}$ & $7 / 16 / 91$ \\
\hline & 16.25 & 30.57 & 172.3 & $111 \pm 13$ & & & $9 / 23 / 91$ \\
\hline & 16.24 & 30.56 & 169.3 & $90 \pm 14$ & & & $9 / 23 / 91$ \\
\hline \multirow{11}{*}{$\begin{array}{c}4 \\
\text { South }\end{array}$} & 16.22 & 30.54 & 166.3 & $370 \pm 23$ & & & $9 / 23 / 91$ \\
\hline & 16.20 & 30.52 & 169.3 & $596 \pm 28$ & & & 9/23/91 \\
\hline & 16.19 & 30.51 & 172.3 & $459 \pm 28$ & & & $9 / 23 / 91$ \\
\hline & 16.19 & 30.51 & 173.3 & $290 \pm 21$ & 18.3 & $\mathbf{N}$ & $7 / 16 / 91$ \\
\hline & 16.18 & 30.50 & 176.3 & $56 \pm 8$ & 19.6 & $\mathbf{N}$ & $7 / 17 / 91$ \\
\hline & 16.18 & 30.49 & 179.3 & $432 \pm 24$ & 21.2 & $\mathbf{N}$ & $7 / 17 / 91$ \\
\hline & 16.17 & 30.48 & 182.3 & $599 \pm 28$ & 26.1 & $\mathbf{N}$ & $7 / 17 / 91$ \\
\hline & 16.16 & 30.48 & 185.3 & $63 \pm 14$ & 28.2 & $Y$ & $7 / 17 / 91$ \\
\hline & 16.16 & 30.47 & 188.3 & $13 \pm 4$ & 28.6 & $\mathrm{Y}$ & $7 / 17 / 91$ \\
\hline & 16.15 & 30.46 & 191.3 & $20 \pm 4$ & 28.5 & $Y$ & $7 / 17 / 91$ \\
\hline & 16.14 & 30.46 & 194.3 & $23 \pm 12$ & 28.6 & $\mathrm{Y}$ & $7 / 17 / 91$ \\
\hline \multirow{14}{*}{$\begin{array}{c}\mathfrak{3} \\
\text { North }\end{array}$} & 15.50 & 31.63 & 194.5 & $102 \pm 11$ & 28.6 & $\mathbf{Y}$ & $7 / 16 / 91$ \\
\hline & 15.50 & 31.63 & 191.5 & $110 \pm 10$ & 28.5 & $\mathbf{Y}$ & $7 / 16 / 91$ \\
\hline & 15.49 & 31.63 & 188.5 & $93 \pm 10$ & 28.7 & $Y$ & $7 / 16 / 91$ \\
\hline & 15.48 & 31.63 & 185.5 & $484 \pm 22$ & 29.0 & $\mathbf{N}$ & $7 / 16 / 91$ \\
\hline & 15.47 & 31.63 & 182.5 & $272 \pm 22$ & 29.1 & $\mathbf{N}$ & $7 / 16 / 91$ \\
\hline & 15.46 & 31.63 & 179.5 & $579 \pm 30$ & 29.2 & $\mathbf{N}$ & $7 / 16 / 91$ \\
\hline & 15.44 & 31.63 & 176.5 & $587 \pm 33$ & 19.7 & $\mathbf{N}$ & $7 / 16 / 91$ \\
\hline & 15.41 & 31.63 & 173.5 & $223 \pm 24$ & 19.2 & $\mathbf{N}$ & $7 / 16 / 91$ \\
\hline & 15.40 & 31.64 & 172.5 & $181 \pm 21$ & & & $9 / 19 / 91$ \\
\hline & 15.38 & 31.64 & 169.5 & $95 \pm 11$ & & & $9 / 19 / 91$ \\
\hline & 15.37 & 31.64 & 166.5 & $57 \pm 20$ & & & $9 / 19 / 91$ \\
\hline & 15.36 & 31.64 & 163.5 & $1082 \pm 40$ & & & 9/19/91 \\
\hline & 15.36 & 31.64 & 160.5 & $529 \pm 28$ & & & $9 / 19 / 91$ \\
\hline & 15.34 & 31.64 & 157.5 & $461 \pm 33$ & & & $9 / 19 / 91$ \\
\hline
\end{tabular}


Table A.1. (Continued)

\begin{tabular}{|c|c|c|c|c|c|c|c|}
\hline Transect & Lat $81 \mathrm{~N}$ & Lon $33 W$ & Deph & Countrate & Temp & $\mathrm{Veg}$ & Data Date \\
\hline & $(\min )$ & (min) & (ft $\mathrm{msl})$ & $(\mathrm{cpm})$ & $(\operatorname{deg} C)$ & & \\
\hline 5 & 15.33 & 31.64 & 156.5 & $352 \pm 28$ & & & 9/19/91 \\
\hline \multirow[t]{15}{*}{ South } & 15.29 & 31.65 & 160.5 & $740 \pm 35$ & & & $9 / 19 / 91$ \\
\hline & 15.28 & 31.65 & 163.5 & $20 \pm 4$ & & & $9 / 19 / 91$ \\
\hline & 15.27 & 31.65 & 166.5 & $623 \pm 34$ & & & 9/19/91 \\
\hline & 15.26 & 31.65 & 169.5 & $348 \pm 24$ & & & 9/19/91 \\
\hline & 15.26 & 31.65 & 172.0 & $380 \pm 20$ & & & $10 / 01 / 91$ \\
\hline & 15.26 & 31.65 & 172.5 & $365 \pm 29$ & & & $9 / 19 / 91$ \\
\hline & 15.26 & 31.65 & 173.5 & $721 \pm 29$ & 20.1 & $\mathbf{N}$ & $7 / 16 / 91$ \\
\hline & 15.25 & 31.65 & 176.5 & $420 \pm 33$ & 23.8 & $\mathbf{N}$ & $7 / 16 / 91$ \\
\hline & 15.25 & 31.65 & 179.5 & $397 \pm 26$ & 25.0 & $\mathbf{N}$ & $7 / 16 / 91$ \\
\hline & 15.24 & 31.65 & 182.5 & $158 \pm 13$ & 28.9 & $\mathbf{N}$ & $7 / 16 / 91$ \\
\hline & 15.24 & 31.65 & 182.5 & $11 \pm 3$ & 29.2 & $\mathbf{N}$ & $7 / 16 / 91$ \\
\hline & 15.24 & 31.65 & 185.5 & $292 \pm 23$ & 29.2 & $\mathbf{Y}$ & $7 / 16 / 91$ \\
\hline & 15.23 & 31.65 & 188.5 & $85 \pm 10$ & 29.4 & $\mathbf{Y}$ & $7 / 16 / 91$ \\
\hline & 15.22 & 31.65 & 191.5 & $95 \pm 10$ & 29.1 & $\mathbf{Y}$ & $7 / 16 / 91$ \\
\hline & 15.21 & 31.65 & 194.5 & $33 \pm 9$ & 29.5 & $\mathbf{Y}$ & $7 / 16 / 91$ \\
\hline 6 & 14.71 & 31.57 & 192.9 & $20 \pm 9$ & 31.2 & $\mathbf{Y}$ & $7 / 23 / 91$ \\
\hline \multirow[t]{15}{*}{ West } & 14.71 & 31.55 & 189.9 & $97 \pm 15$ & 30.5 & $\mathbf{Y}$ & $7 / 23 / 91$ \\
\hline & 14.71 & 31.53 & 186.9 & $26 \pm 9$ & 30.1 & $\mathbf{Y} / \mathbf{N}$ & $7 / 23 / 91$ \\
\hline & 14.70 & 31.51 & 183.9 & $7 \pm 4$ & 29.2 & $\mathbf{N}$ & $7 / 23 / 91$ \\
\hline & 14.70 & 31.49 & 180.9 & $22 \pm 13$ & 24.6 & $\mathbf{N}$ & $7 / 23 / 91$ \\
\hline & 14.70 & 31.47 & 177.9 & $12 \pm 6$ & 23.4 & $\mathrm{~N}$ & $7 / 23 / 91$ \\
\hline & 14.69 & 31.45 & 174.9 & $67 \pm 15$ & 20.2 & $\mathbf{N}$ & $7 / 23 / 91$ \\
\hline & 14.69 & 31.43 & 172.3 & $471 \pm 23$ & & & $9 / 23 / 91$ \\
\hline & 14.69 & 31.43 & 171.9 & $505 \pm 29$ & 18.6 & $\mathbf{N}$ & $7 / 23 / 91$ \\
\hline & 14.69 & 31.41 & 169.3 & $250 \pm 21$ & & & $9 / 23 / 91$ \\
\hline & 14.68 & 31.40 & 166.3 & $515 \pm 27$ & & & $9 / 23 / 91$ \\
\hline & 14.68 & 31.38 & 163.3 & $175 \pm 18$ & & & $9 / 23 / 91$ \\
\hline & 14.68 & 31.37 & 160.3 & $375 \pm 23$ & & & $9 / 23 / 91$ \\
\hline & 14.68 & 31.34 & 157.3 & $274 \pm 17$ & & & $9 / 23 / 91$ \\
\hline & 14.67 & 31.31 & 154.3 & $197 \pm 18$ & & & $9 / 23 / 91$ \\
\hline & 14.67 & 31.29 & 151.3 & $335 \pm 23$ & & & $9 / 23 / 91$ \\
\hline
\end{tabular}


Table A.1. (Continued)

\begin{tabular}{|c|c|c|c|c|c|c|c|}
\hline Transect & Lat $81 \mathrm{~N}$ & Lon $33 W$ & Depth & Countrate & Temp & Veg & Data Date \\
\hline & $(\mathrm{min})$ & $(\min )$ & (ft msl) & (cpm) & $(\operatorname{deg} C)$ & & \\
\hline \multirow{17}{*}{$\begin{array}{c}6 \\
\text { East }\end{array}$} & 14.66 & 31.21 & 148.3 & $634 \pm 32$ & & & $9 / 23 / 91$ \\
\hline & 1465 & 31.16 & 151.3 & $1032 \pm 38$ & & & $9 / 23 / 91$ \\
\hline & 14.65 & 31.15 & 154.3 & $864 \pm 33$ & & & $9 / 23 / 91$ \\
\hline & 14.65 & 31.14 & 157.3 & $220 \pm 18$ & & & $9 / 23 / 91$ \\
\hline & 14.65 & 31.13 & 160.3 & $547 \pm 24$ & & & $9 / 23 / 91$ \\
\hline & 14.65 & 31.12 & 163.3 & $488 \pm 22$ & & & $9 / 23 / 91$ \\
\hline & 14.65 & 31.11 & 166.3 & $392 \pm 20$ & & & $9 / 23 / 91$ \\
\hline & 14.64 & 31.10 & 169.3 & $251 \pm 21$ & & & $9 / 23 / 91$ \\
\hline & 14.64 & 31.09 & 171.9 & $460 \pm 31$ & 18.4 & $\mathbf{N}$ & $7 / 23 / 91$ \\
\hline & 14.64 & 31.09 & 172.3 & $451 \pm 21$ & & & $9 / 23 / 91$ \\
\hline & 14.64 & 31.08 & 174.9 & $562 \pm 32$ & 20.3 & $\mathbf{N}$ & $7 / 23 / 91$ \\
\hline & 14.64 & 31.07 & 177.9 & $921 \pm 42$ & 24.5 & $\mathbf{N}$ & $7 / 23 / 91$ \\
\hline & 14.64 & 31.06 & 180.9 & $59 \pm 13$ & 27.4 & $\mathbf{N}$ & $7 / 23 / 91$ \\
\hline & 14.64 & 31.06 & 183.9 & $45 \pm 10$ & 28.8 & $\mathbf{N}$ & $7 / 23 / 91$ \\
\hline & 14.64 & 31.05 & 186.9 & $163 \pm 20$ & 29.3 & $Y$ & $7 / 23 / 91$ \\
\hline & 14.63 & 31.04 & 189.9 & $54 \pm 16$ & 29.7 & $\mathrm{Y}$ & $7 / 23 / 91$ \\
\hline & 14.63 & 31.03 & 192.9 & $13 \pm 6$ & 29.7 & $\mathrm{Y}$ & $7 / 23 / 91$ \\
\hline \multirow{19}{*}{$\begin{array}{c}7 \\
\text { West }\end{array}$} & 13.99 & 31.51 & 194.0 & $65 \pm 8$ & 28.5 & $Y$ & $7 / 18 / 91$ \\
\hline & 14.00 & 31.48 & 191.0 & $215 \pm 19$ & 27.7 & $\mathrm{Y}$ & $7 / 18 / 91$ \\
\hline & 14.01 & 31.45 & 188.0 & $310 \pm 21$ & 28.1 & $\mathrm{Y}$ & $7 / 18 / 91$ \\
\hline & 14.02 & 31.43 & 185.0 & $179 \pm 14$ & 27.9 & $\mathrm{Y} / \mathrm{N}$ & $7 / 18 / 91$ \\
\hline & 14.03 & 31.42 & 182.0 & $80 \pm 16$ & 26.8 & $\mathrm{~N}$ & $7 / 18 / 91$ \\
\hline & 14.04 & 31.39 & 179.0 & $322 \pm 20$ & 22.3 & $\mathrm{~N}$ & $7 / 18 / 91$ \\
\hline & 14.05 & 31.34 & 176.0 & $327 \pm 20$ & 21.3 & $\mathrm{~N}$ & $7 / 18 / 91$ \\
\hline & 14.07 & 31.30 & 173.0 & $336 \pm 22$ & 18.4 & $\mathrm{~N}$ & $7 / 18 / 91$ \\
\hline & 14.07 & 31.29 & 172.3 & $286 \pm 21$ & & & $9 / 23 / 91$ \\
\hline & 14.09 & 31.25 & 169.3 & $469 \pm 28$ & & & $9 / 23 / 91$ \\
\hline & 14.10 & 31.22 & 166.3 & $677 \pm 29$ & & & $9 / 23 / 91$ \\
\hline & 14.11 & 31.18 & 163.3 & $384 \pm 23$ & & & $9 / 23 / 91$ \\
\hline & 14.12 & 31.15 & 160.3 & $518 \pm 27$ & & & $9 / 23 / 91$ \\
\hline & 14.12 & 31.15 & 157.3 & $132 \pm 12$ & & & $9 / 23 / 91$ \\
\hline & 14.13 & 31.14 & 154.3 & $227 \pm 15$ & & & $9 / 23 / 91$ \\
\hline & 14.13 & 31.14 & 151.3 & $42 \pm 6$ & & & $9 / 23 / 91$ \\
\hline & 14.14 & 31.12 & 148.3 & $281 \pm 21$ & & & $9 / 23 / 91$ \\
\hline & 14.15 & 31.08 & 145.3 & $623 \pm 30$ & & & $9 / 23 / 91$ \\
\hline & 14.16 & 31.05 & 142.3 & $684 \pm 28$ & & & $9 / 23 / 91$ \\
\hline
\end{tabular}


Table A.1. (Continued)

\begin{tabular}{|c|c|c|c|c|c|c|c|}
\hline Transect & Lat $81 \mathrm{~N}$ & Lon $33 \mathrm{~W}$ & Depth & Countrate & Temp & Veg & Data Date \\
\hline & $(\min )$ & $(\min )$ & (ft msl) & $(\mathrm{cpm})$ & $(\operatorname{deg} C)$ & & \\
\hline 7 & 14.17 & 31.01 & 145.3 & $470 \pm 27$ & & & $9 / 23 / 91$ \\
\hline \multirow[t]{17}{*}{ East } & 14.19 & 30.98 & 148.3 & $513 \pm 23$ & & & $9 / 23 / 91$ \\
\hline & 14.19 & 30.95 & 151.3 & $678 \pm 26$ & & & $9 / 23 / 91$ \\
\hline & 14.20 & 30.93 & 154.3 & $390 \pm 24$ & & & $9 / 23 / 91$ \\
\hline & 14.20 & 30.91 & 157.3 & $450 \pm 29$ & & & $9 / 23 / 91$ \\
\hline & 14.21 & 30.90 & 160.3 & $372 \pm 24$ & & & $9 / 23 / 91$ \\
\hline & 14.21 & 30.89 & 163.3 & $262 \pm 16$ & & & $9 / 23 / 91$ \\
\hline & 14.21 & 30.88 & 166.3 & $216 \pm 20$ & & & $9 / 23 / 91$ \\
\hline & 14.22 & 30.88 & 169.3 & $384 \pm 24$ & & & 9/23/91 \\
\hline & 14.22 & 30.87 & 172.3 & $632 \pm 33$ & & & $9 / 23 / 91$ \\
\hline & 14.22 & 30.87 & 173.0 & $428 \pm 28$ & 18.6 & $\mathbf{N}$ & $7 / 18 / 93$ \\
\hline & 14.22 & 30.87 & 176.0 & $338 \pm 26$ & 20.2 & $\mathbf{N}$ & $7 / 18 / 93$ \\
\hline & 14.22 & 30.86 & 179.0 & $701 \pm 30$ & 21.2 & $\mathbf{N}$ & $7 / 18 / 93$ \\
\hline & 14.22 & 30.85 & 182.0 & $442 \pm 27$ & 26.7 & $\mathbf{N}$ & $7 / 18 / 93$ \\
\hline & 14.22 & 30.85 & 185.0 & $83 \pm 9$ & 29.6 & $\mathrm{Y}$ & $7 / 18 / 93$ \\
\hline & 14.23 & 30.85 & 188.0 & $113 \pm 11$ & 29.5 & $\mathbf{Y}$ & $7 / 18 / 93$ \\
\hline & 14.23 & 30.84 & 191.0 & $23 \pm 9$ & 29.7 & $\mathrm{Y}$ & $7 / 18 / 93$ \\
\hline & 14.23 & 30.84 & 194.0 & $45 \pm 7$ & 30.5 & $\mathrm{Y}$ & $7 / 18 / 93$ \\
\hline 8 & 14.46 & 32.19 & 194.0 & $40 \pm 7$ & 29.3 & $Y$ & $7 / 18 / 91$ \\
\hline \multirow[t]{9}{*}{ North } & 14.45 & 32.19 & 191.0 & $68 \pm 9$ & 29.4 & $\mathbf{Y}$ & $7 / 18 / 91$ \\
\hline & 14.44 & 32.19 & 188.0 & $98 \pm 15$ & 29.3 & $\mathbf{Y}$ & $7 / 18 / 91$ \\
\hline & 14.43 & 32.19 & 185.0 & $39 \pm 7$ & 27.9 & $\mathbf{N}$ & $7 / 18 / 91$ \\
\hline & 14.42 & 32.19 & 182.0 & $115 \pm 14$ & 28.2 & $\mathbf{N}$ & $7 / 18 / 91$ \\
\hline & 14.41 & 32.18 & 179.0 & $122 \pm 14$ & 25.3 & $\mathbf{N}$ & $7 / 18 / 91$ \\
\hline & 14.39 & 32.18 & 176.0 & $101 \pm 13$ & 21.4 & $\mathbf{N}$ & $7 / 18 / 91$ \\
\hline & 14.36 & 32.18 & 173.0 & $92 \pm 14$ & 19.9 & $\mathbf{N}$ & $7 / 18 / 91$ \\
\hline & 14.36 & 32.18 & 172.3 & $132 \pm 14$ & & & $9 / 23 / 91$ \\
\hline & 14.33 & 32.18 & 169.3 & $125 \pm 15$ & & & $9 / 23 / 91$ \\
\hline 8 & 14.27 & 32.17 & 166.3 & $600 \pm 28$ & & & $9 / 23 / 91$ \\
\hline \multirow[t]{10}{*}{ South } & 14.24 & 32.16 & 169.3 & $370 \pm 23$ & & & $9 / 23 / 91$ \\
\hline & 14.22 & 32.16 & 172.3 & $1055 \pm 37$ & & & $9 / 23 / 91$ \\
\hline & 14.21 & 32.16 & 173.0 & $288 \pm 17$ & 18.7 & $\mathbf{N}$ & $7 / 18 / 91$ \\
\hline & 14.19 & 32.16 & 176.0 & $229 \pm 16$ & 20.5 & $\mathbf{N}$ & $7 / 18 / 91$ \\
\hline & 14.18 & 32.16 & 179.0 & $115 \pm 15$ & 21.8 & $\mathbf{N}$ & $7 / 18 / 91$ \\
\hline & 14.17 & 32.16 & 182.0 & $25 \pm 5$ & 27.9 & $\mathbf{N}$ & $7 / 18 / 91$ \\
\hline & 14.16 & 32.16 & 185.0 & $122 \pm 11$ & 28.0 & $\mathrm{Y} / \mathrm{N}$ & $7 / 18 / 91$ \\
\hline & 14.15 & 32.15 & 188.0 & $131 \pm 12$ & 28.1 & $\mathbf{Y}$ & $7 / 18 / 91$ \\
\hline & 14.14 & 32.15 & 191.0 & $74 \pm 10$ & 28.3 & $Y$ & $7 / 18 / 91$ \\
\hline & 14.12 & 32.15 & 194.0 & $46 \pm 7$ & 28.6 & $\mathbf{Y}$ & $7 / 18 / 91$ \\
\hline
\end{tabular}


Table A.1. (Continued)

\begin{tabular}{|c|c|c|c|c|c|c|c|}
\hline Transect & Lat $81 \mathrm{~N}$ & Lon $33 W$ & Depth & Countrate & Temp & Veg & Data Date \\
\hline & $(\mathrm{min})$ & $(\mathrm{min})$ & $(\mathrm{ft} \mathrm{msl})$ & (cpm) & $(\operatorname{deg} C)$ & & \\
\hline 9 & 14.71 & 32.97 & 194.0 & $37 \pm 6$ & 28.8 & $\mathbf{Y}$ & $7 / 18 / 91$ \\
\hline \multirow[t]{6}{*}{ West } & 14.72 & 32.97 & 191.0 & $101 \pm 11$ & 28.0 & $\mathbf{Y} / \mathbf{N}$ & $7 / 18 / 91$ \\
\hline & 14.73 & 32.94 & 188.0 & $119 \pm 13$ & 27.8 & $\mathbf{N}$ & $7 / 18 / 91$ \\
\hline & 14.74 & 32.90 & 185.0 & $233 \pm 19$ & 28.1 & $\mathbf{N}$ & $7 / 18 / 91$ \\
\hline & 14.76 & 32.86 & 182.0 & $2 \pm 1$ & 27.3 & $\mathbf{N}$ & $7 / 18 / 91$ \\
\hline & 14.77 & 32.82 & 179.0 & $823 \pm 31$ & 23.5 & $\mathbf{N}$ & $7 / 18 / 91$ \\
\hline & 14.78 & 32.79 & 176.0 & $133 \pm 13$ & 22.8 & $\mathbf{N}$ & $7 / 18 / 91$ \\
\hline 9 & 14.78 & 32.79 & 176.0 & $307 \pm 19$ & 22.9 & $\mathbf{N}$ & $7 / 18 / 91$ \\
\hline \multirow[t]{6}{*}{ East } & 14.79 & 32.76 & 179.0 & $841 \pm 31$ & 22.5 & $\mathbf{N}$ & $7 / 18 / 91$ \\
\hline & 14.79 & 32.75 & 182.0 & $19 \pm 5$ & 26.9 & $\mathbf{N}$ & $7 / 18 / 91$ \\
\hline & 14.80 & 32.75 & 185.0 & $142 \pm 14$ & 27.8 & $Y$ & $7 / 18 / 91$ \\
\hline & 14.80 & 32.74 & 188.0 & $92 \pm 13$ & 28.0 & $Y$ & $7 / 18 / 91$ \\
\hline & 14.80 & 32.74 & 191.0 & $2 \pm 2$ & 28.2 & $Y$ & $7 / 18 / 91$ \\
\hline & 14.80 & 32.73 & 194.0 & $12 \pm 3$ & 28.8 & $Y$ & $7 / 18 / 91$ \\
\hline 10 & 15.34 & 31.54 & 157.0 & $291 \pm 17$ & & & $11 / 05 / 91$ \\
\hline North & 15.33 & 31.53 & 154.0 & $834 \pm 36$ & & & $11 / 05 / 91$ \\
\hline \multirow[t]{9}{*}{ South } & 15.29 & 31.53 & 155.0 & $1664 \pm 49$ & & & $11 / 05 / 91$ \\
\hline & 15.28 & 31.53 & 154.0 & $1568 \pm 46$ & & & $11 / 05 / 91$ \\
\hline & 15.28 & 31.53 & 154.0 & $2397 \pm 58$ & & & $11 / 05 / 91$ \\
\hline & 15.28 & 31.54 & 155.0 & $2913 \pm 66$ & & & $11 / 05 / 91$ \\
\hline & 15.28 & 31.51 & 154.0 & $1226 \pm 42$ & & & $11 / 05 / 91$ \\
\hline & 15.27 & 31.53 & 156.0 & $731 \pm 33$ & & & $11 / 05 / 91$ \\
\hline & 15.26 & 31.53 & 157.0 & $785 \pm 32$ & & & $11 / 05 / 91$ \\
\hline & 15.24 & 31.53 & 160.0 & $808 \pm 34$ & & & $11 / 05 / 91$ \\
\hline & 15.23 & 31.54 & 166.0 & $748 \pm 33$ & & & $11 / 05 / 91$ \\
\hline
\end{tabular}




\section{Appendix B. Analysis of Vegetation and Temperature at Pond Bottom}

The data for vegetation and temperature measurements are given in Table A.1. These measurements were made for transects $2-9$ and are averaged as a function of bottom depth in Figure 8. The temperature measurements were made with a thermocouple reading thermometer, the sensor of which was attached to the lower screening shield of the detector. The presence of vegetation was determined by visual observation and/or by the patterns on the Lowrance depth finder.

The smoothed data plotted in Figure 8 was obtained using the unsmoothed raw data, as plotted in Figure B.1. The temperature plot is self-explanatory.
The vegetation plot uses a value of 1.0 for observed vegetation ( $Y$ in Table A.1), 0.5 for borderline vegetation $(\mathrm{Y} / \mathrm{N})$, and 0.0 for no vegetation $(\mathrm{N})$. This numerical treatment essentially treats the data as probabilities for observing vegetation. The numerical data of Figure B.1 were smoothed by point averaging. Each resulting averaged value in Figure 8 uses the 19 points from Figure B.1, including a single point and adjacent 18 points (9 above and 9 below) at monotonic depths. Corresponding smoothed average depths are assigned to each smoothed vegetation and temperature value. 

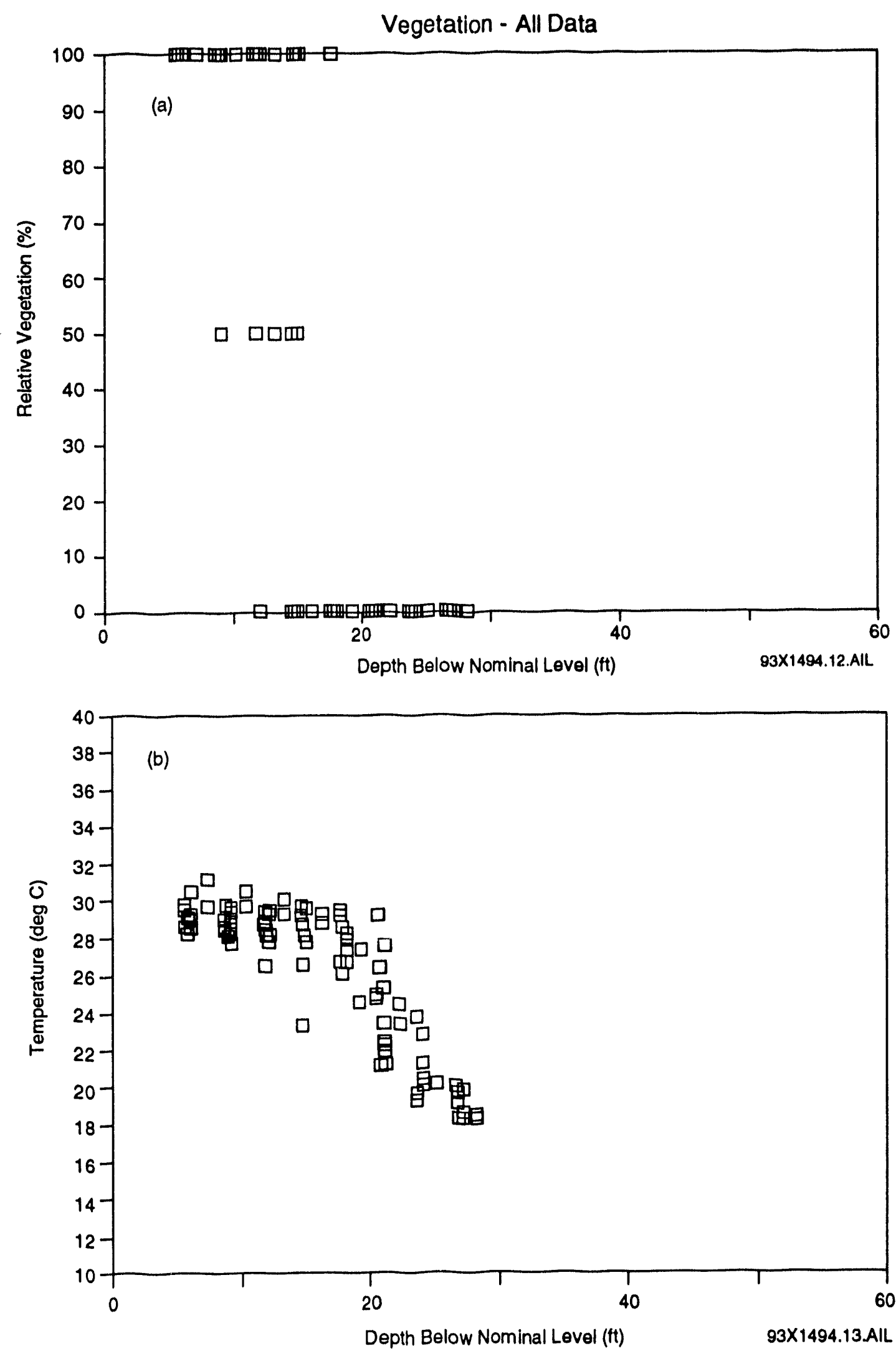

Figure B-1. All Transect Measurements of (a) Vegetation and (b) Sediment Temperature. 


\section{Appendix C. Underwater HPGe Calibration Studies}

Calculations of the underwater HPGe ${ }^{137} \mathrm{Cs}$ calibration yield $\mathrm{A} / \mathrm{R}$ in units of $\mathrm{pCi} / \mathrm{m}^{2} / \mathrm{cpm}$ from the expression

$$
\mathrm{R}=\mathrm{A} \int_{0}^{\mathrm{h}} \int_{0}^{\mathrm{a}} \mathrm{P}(\mathrm{z}) \mathrm{I}_{\gamma} \in(\mathrm{r}, \mathrm{z}) 2 \pi \mathrm{rdrdz},
$$

which is identical to Eq. 3 of the main text except that $\bar{P}(z)$ has been replaced by $P(z)$. The text defines $\epsilon(r, z)$ and other parameters relative to Eqs. 1-3. The BASIC code EFFUGDBD was developed for the calculations; it also produces $\mathrm{A} / \mathrm{R}$ in units of $\mathrm{pCi} / \mathrm{kg} / \mathrm{cpm}$ and $\mathrm{pCi} / \mathrm{m}^{3} / \mathrm{cpm}$ for comparison. The code listing and an example run are given in Figure C.1.

Calculations for $\mathrm{A} / \mathrm{R}$ are given in Table C.1, and are based on data given in the code listing and example. Using the notations of Eqs. 1-3 and Figure 10 of the main text, code parameters used are:

\section{Manual Inputs}

$$
\begin{array}{lll}
\mathrm{z}_{0} & = & \text { detector center to sediment } \\
& \text { surface (in) }=5 \\
\mathrm{z}_{\mathrm{D}} & = & \text { detector can radius (in) }=1.5 \\
\epsilon_{A}(0,0)= & \text { unattenuated efficiency at } \\
& \text { sediment }=0.00294 \\
\mathrm{~s}_{\mathrm{w}} & = & \text { attenuation coefficient of } \\
& \text { water }\left(\mathrm{cm}^{2}\right)=0.085 \\
\mathrm{p}_{\mathrm{w}} & = & \text { density of water }\left(\mathrm{g} / \mathrm{cm}^{3}\right)=1 \\
\mathrm{~s}_{\mathrm{s}} & = & \text { attenuation coefficient of sediment } \\
& \left(\mathrm{cm}^{2} / \mathrm{g}\right)=0.085 \\
\mathrm{a} & = & \text { radial integral max } \mathrm{R}(\mathrm{cm})=70 \\
\mathrm{dr} & = & \text { radial integral step } \mathrm{DR}(\mathrm{cm})=2 \\
\mathrm{~b} & = & \text { axial integral max } \\
& \mathrm{Z}(\mathrm{cm})=\text { core depth } \leq 38 \\
\mathrm{dz} & = & \text { axial integral step } \mathrm{DZ}(\mathrm{cm})=1
\end{array}
$$

Data within code

$$
\begin{aligned}
& \mathrm{I}_{\gamma} \quad=\text { fraction of } 662 \mathrm{keV} \text { gammas per } \\
& { }^{137} \mathrm{Cs} \text { decay }=0.8521 \\
& \mathrm{dpm} / \mathrm{pCi}=\text { conversion factor }=0.037 \times 60= \\
& 2.22
\end{aligned}
$$

Datainfiles

$$
\begin{aligned}
\mathrm{p}_{S}(\mathrm{z})= & \begin{array}{l}
\text { density of sediment between core } \\
\text { levels } \mathrm{z} \text { and } \mathrm{z}+1
\end{array} \\
\mathrm{P}(\mathrm{z})= & \begin{array}{l}
\text { probability of }{ }^{137} \mathrm{Cs} \text { between core } \\
\text { levels } \mathrm{z} \text { and } \mathrm{z}+1 \text { per code } \\
\text { normalization of raw data. }
\end{array}
\end{aligned}
$$

The input $\epsilon_{A}(0,0)=0.002984$ was determined by counting an effective point-source ${ }^{137} \mathrm{Cs}$ standard directly under the bottom screen of the detector while in air.

The calculations of Table $C .1$ yield an average A/R of $17068 \mathrm{pCi} / \mathrm{m}^{2} / \mathrm{cpm}$ for Par Pond sediment. Pending availability of additional core samples from SREL, the accuracy of $A / R$ may be improved in the future. The table also includes test calculations showing that the integration mesh $(\mathrm{dr}=2, \mathrm{dz}=1)$ and volume size are sufficiently accurate for the calculations. The volume is cylindrical with radius $\mathrm{a}=70 \mathrm{~cm}$ and $\mathrm{h}$ $\leq 38 \mathrm{~cm}$ for the individual the core samples. Because all core samples extended to depths where ${ }^{137} \mathrm{Cs}$ had decreased to negligible levels, it is assumed that all ${ }^{137} \mathrm{Cs}$ is contained within a cylinder of $h=38 \mathrm{~cm}$. The choice of volume radius $a=70 \mathrm{~cm}$ was tested for a uniform $p_{s}(z)=$ $1.5 \mathrm{~g} / \mathrm{cm}^{3}$ and uniform $\mathrm{P}(\mathrm{z})=1 / 38 \mathrm{~cm}^{-1}$ by comparing $A / R$ calculations for $a=50,70$, and $100 \mathrm{~cm}$. Differences between the resulting A/R in Table C. 1 are very small, implying that an $\mathrm{a}=$ $70 \mathrm{~cm}$ produces $A / R$ to within less than $1 \%$ uncertainty. The difference in using a $1 \mathrm{~cm}$ or 2 $\mathrm{cm}$ mesh in the integration is also shown to be $0.2 \%$ for similar examples given in the table. Thus, the code integrations were quite adequate for yielding $A / R$ for Par Pond sediment.

During the process of developing the $A / R$ calculations, interest arose concerning the type of factor that is most appropriate for a given application. A calculational study was performed for uniform ${ }^{137} \mathrm{Cs}$ in sediment contained within a variety of sediment depths. The resulting $A / R$ in $\mathrm{nCi} / \mathrm{m}^{2} / \mathrm{cpm}$ and $\mathrm{pCi} / \mathrm{kg} / \mathrm{cpm}$ units are plotted as a function of $b$ in Figure C.2. Here, the $\mathrm{nCi} / \mathrm{m}^{2} / \mathrm{cpm}$ value is relatively constant for low $\mathrm{h}$ but increases rapidly for larger $h$. By contrast, the $\mathrm{nCi} / \mathrm{kg} / \mathrm{cpm}$ value is relatively constant for large h, but increases rapidly with 
lower h. From Figure 11, it is clear that most of the Par Pond ${ }^{137} \mathrm{Cs}$ is distributed at shallow depths or low $\mathrm{h}$, and thus an $\mathrm{A} / \mathrm{R}$ in $\mathrm{nCi} / \mathrm{m}^{2} / \mathrm{cpm}$ units is most appropriate.

Table C.1. Calculations of A/R

Sediment Core Measurements ${ }^{a}$

$\mathrm{P}(\mathrm{z})$ and $\mathrm{p}_{\mathrm{s}}(\mathrm{z})$ data in code listing (Figure $\left.\mathrm{C} .1\right) \mathrm{a}=70 \mathrm{~cm}, \mathrm{dr}=2 \mathrm{~cm}, \mathrm{~h}=($ below), $\mathrm{dz}=1 \mathrm{~cm}$

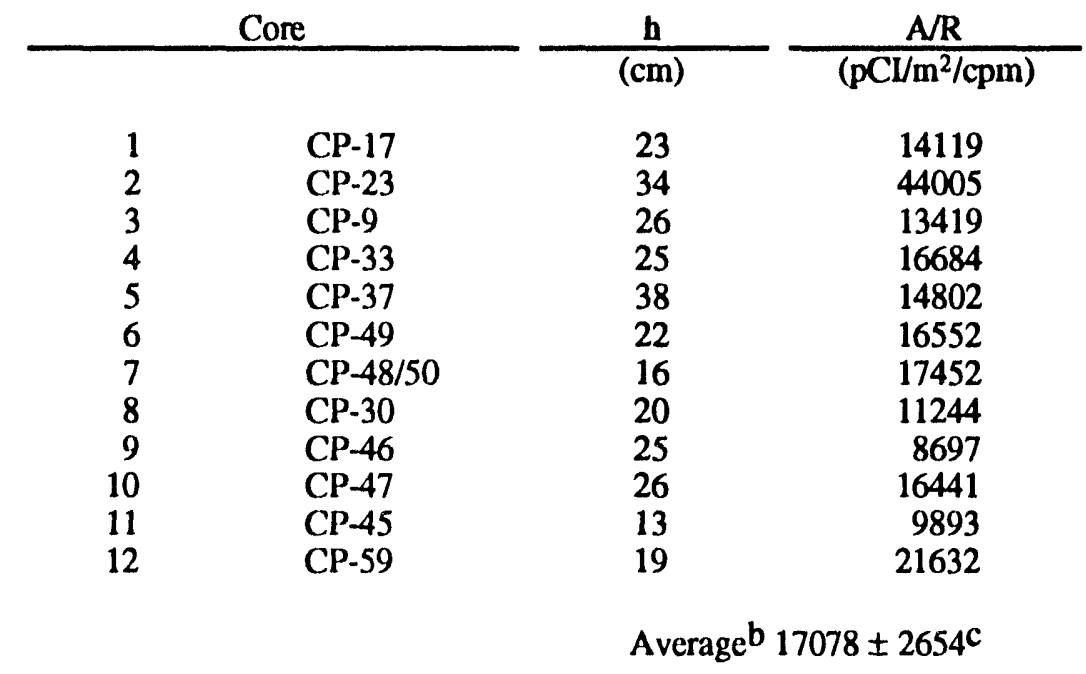

${ }^{a}$ Core data including labels from F.W. Whicker group, SREL.

$\checkmark$ Text expresses as $0.0171 \pm 0.0027 \mu \mathrm{Ci} / \mathrm{m}^{2} / \mathrm{cpm}$.

${ }^{c}$ Error is standard deviation of mean.

\section{Calculation Tests for Sensitivity}

Sensitivity

parameters

$\mathrm{p}_{\mathrm{S}}(\mathbf{z})$

a dr

h

dz

$\mathrm{A} \mathbf{Z}$

$\begin{array}{llllll}\left(\mathrm{g} / \mathrm{cm}^{3}\right) & (\mathrm{cm}) & (\mathrm{cm}) & (\mathrm{cm}) & (\mathrm{cm}) & \left(\mathrm{pCi} / \mathrm{m}^{2} / \mathrm{cpm}\right)(\mathrm{rel})\end{array}$

$\begin{array}{clllllll}\text { a } & 1.5 & 50 & 2 & 38 & 1 & 47204 & 1.013 \\ & \text { constant } & 70 & 2 & 38 & 1 & 46578 \equiv 1.000 \\ & & 100 & 2 & 38 & 1 & 46495 & 0.998 \\ \mathrm{dr}, \mathrm{dz} & 1.1 & 50 & 1 & 50 & 1 & 46090 \equiv 1.000 \\ & \begin{array}{l}\text { constant } \\ \end{array} & 50 & 2 & 50 & 2 & 46200 & 1.002 \\ \mathrm{dz} & 1.1 & 70 & 2 & 10 & 1 & & 12441 \equiv 1.000 \\ & \text { constant } & 70 & 2 & 10 & 2 & 12464 & 1.002\end{array}$


Figure C.1 EFFUGDPD Code listing and example.

\section{Code Linting}

10 REA A : EFFUGDPD. BAS

11 DIM DS (50), DSZ (50)

12 SUND 0

13 FOR I=0 TO 37

14 READ DS (I) :SURD $=\operatorname{SUND+DS}(I)$

$15 \mathrm{DSZ}(I)=S \mathrm{NDD} /(I+1)$

16 REM PRINT I, DS (I), DSZ (I)

17 NEXT I

20 DIM $P(50)$

21 READ PTOT

$22 \mathrm{~N}=0$

23 READ $P(N): P(N)=P(N) /$ PTOT

24 IF $P(N)$ *PTOT $\rightarrow-1$ THEN N-N+1:GOTO 23

$25 \mathrm{SUN}=0$

26 FOR I=0 TO N-1

$27 P(I)=N \oplus P(I)$

30 SUI $-P(I)+$ SUIS

35 NEXT I

40 PRINT SUM

100 REM inputs

110 INPUTnZO detector center to sedinent surface(in) $n ; z 0: 20=2.54 \pitchfork z 0$

115 INPUT"ZR = detector can radius (in)"; ZR:ZR-2.54\#ZR

120 INPUT"EOO = unattenuated detector efficiency at sedinent"; EOO

125 INPUT"DW = density of water $\left(g / \mathrm{cms}_{3}\right) n ; D W$

130 INPUT'UW = attenuation coefficient of water $(\mathrm{cm} / \mathrm{g})$ " ; UW: UW-DW *UW

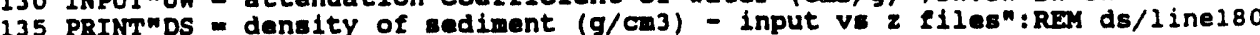

140 INPUT"US - attenuation coefficient of sediment $(\mathrm{cm} / \mathrm{g})$ "; US

$150 \mathrm{REM} F=661$ gama emission rate/pCi Ce-137 (gpm/pCi)

$151 F=.8521 * .037 \star 60$

160 INPUT"Radial integral $\max R(\mathrm{Cm}) n ; L R$

165 INPUT"Radial integral stop DR (Cm)";DR

170 INPUT"Axial integral $\max 2(\mathrm{Cm})$ ":LZ

175 INPUT' Axial integral step DZ (Cm) $\mathrm{NDZ}$

180 DS=DSZ $($ LZ-1)

200 REM CalC

210 FOR $Z=.5 \star D Z$ TO LZ-.5®DZ STEP DZ

225 INTR $=0$

230 FOR $R=.5 * D R$ TO IR-.5*DR STEP DR

$235 \operatorname{SECO}=\operatorname{SQR}\left((\mathrm{Z}+\mathrm{ZO})^{\wedge} 2+R^{\wedge} 2\right) /(20+Z)$

$237 \mathrm{PZ}=\mathrm{P}(\mathrm{INT}(\mathrm{Z}))$

238 USZ $=U S$ DSZ (INT (2)

240 INTR $=$ INTR + PZ $*(20 \wedge 2 /((20+Z) \wedge 2+R \wedge 2)) \star \operatorname{ExP}(-U W \star(Z 0 \star S E C 0-Z R)-U S Z \star Z \star S E C 0)$

* $\mathrm{R} * \mathrm{DR}$

250 NEXT R

260 INTRZ $=$ INTRZ + INTR*DZ

270 NEXT $z$

300 REM results

$310 \mathrm{CPCIG}=\mathrm{F} * \mathrm{DS} * 2 * 3.14159 * \mathrm{EOO} * I N T R Z$

315 PRINT" pCi/m3 per UW CPm = "; $1000000 ! /($ CPCIG/DS)

320 PRINT" pCi/kg per UW CPm $=n_{i}$ 1000/CPCIG

325 PRINT" pCi/m2 per UW cpm $=N_{;}(L Z / 100) * 1000000 ! /($ CPCIG/DS $)$

800 END

Example CP.59

RUN

19

20 = detector center to sediment surface(in)? 5

$\mathrm{ZR}=$ detector can radius(in)? 1.5

EOO = unattenuated detector efficiency at sedinent? .002984

DW = density of water $(9 / \operatorname{cm} 3)$ ? 1

UW = attenuation coefficient of water $(\mathrm{cm} 2 / \mathrm{g}) ? .085$

DS = density of sediment $(\mathrm{g} / \mathrm{cm} 3)$ - input vs z $1110 \mathrm{~s}$

US = attenuation coufficient of eedinent $(\mathrm{Cm} 2 / \mathrm{g}) ? .085$

Radial integral $\max R(\mathrm{Cm})$ ? 70

Radial integral stop DR (cm)? 2

Axial integral max $z$ (Cm)? 19

Axial integral step Dz (Cm)? 1

pCi/m3 per UN CPD = 113854.8

$\mathrm{pCi} / \mathrm{kg}$ per Uw cpm = $=75.21701$

pci/a2 per Un cpm = 21632.41

ok 
Figure C.1 EFFUGDPD Code listing and example. (Continued)

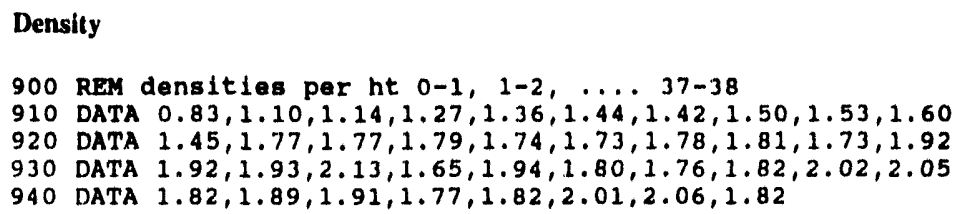

${ }^{137}$ Cesium Probability

Data Sets

1000 REM ptot

1010 REM DATA 63.41

1100 REM p(1)

1110 REM DATA $4.37,7.56,5.29,5.53,5.94,4.95,8.53,3.76,3.70,3.10$

1120 REM DATA $4.05,1.25,1.46,0.74,0.04,0.36,0.71,-0.10,0.79,0.10$

CP.17

1130 REM DATA $0.39,0.71,0.22,-100$

1140 REM DATA $0.0,0.17,0.39,0.62,-100$

2000 REM ptot

2010 REM DATA 655.19

2100 REM $p(1)$

2110 REM DATA $1.2,2.0,4.2,2.8,2.3,3.6,6.6,24.4,82.9,112.1$

2120 REM DATA $123.9,24.3,9.4,8.6,8.9,9.0,8.3,8.0,9.4,13.2$

CP.23

2130 REM DATA $41.3,90.3,37.5,3.88,6.37,5.57,3.25,0.63,0.14,0.0$

2140 REM DATA $0.0,0.17,0.39,0.62,-100$

3000 REM ptot

3010 REM DATA 263.6

3100 REM $P(1)$

3110 REM DATA $15,13.6,19.4,26.2,66.7,62.6,20.3,9.4,5.0,3.2$

3120 REM DATA $2.6,2.8,1.3,1.1,2.2,3.8,3.0,1.2, .9, .8$

3130 REM DATA $.6, .7,0, .3,0, .9,-100$

3140 REM DATA rem $0.0,0.17,0.39,0.62,-100$

4000 REM ptot

4010 REM DATA 172.66

4100 REM $p(1)$

4110 REM DATA $4.41,4.82,6.54,13.25,18.77,27.09,30.08,28.46,13.78,8.05$

4120 REM DATA $4.88,2.56,1.58,1.41, .56, .78,1.0,1.09, .82,1.12, .37, .49$

4130 REM DATA $.62, .06, .07,-100$

5000 REM ptot

5010 REM DATA 142.24

5100 REM $p(i)$

5110 REM DATA $7.44,7.89,6.74,17,21,25,87,18,71,14,34,11,13,8,01,5,59$

5120 REM DATA $4.01,3.42,2.09,1.72,0.79,1.16,0.26,0.24,0.09,0.55,0.08$

5130 REM DATA $0.17,0.27,0.26,0.57,0.67,0.32,-0.39,0.79,0.03,0.63$

5140 REM DATA $0.22,0.32,0.17,0.82,-0.19,-0.02,0.26,-100$

6000 REM ptot

6010 REM DATA 454.70

6100 REM $p(1)$

6110 REM DATA $21.37,24.14,37.55,37.89,35.36,47.85,48.62,46.64,30.41,16.25$

6120 REM DATA $11.26,10.01,17.06,26.75,13.07,8.91,6.86,4.59,3.67,3.83$

6130 REM DATA $1.87,0.73,-100$

7010 REM DATA 420.21

7100 REM $p(1)$

7110 REM DATA $18.20,21.47,22.82,26.43,22.72,27.21,37.59,61.44,59.83,48,40$

7120 REM DATA $40.51,18.53,9.60,4.12,1.00,0.35,-100$

8010 REM DATA 59.75

8100 REM P(1)

8110 REM DATA $5,49,12,25,9,54,8,17,6,25,3,72,3,95,2,78,1,20,1,00$

8120 REM DATA $1.26,0.81,0.26,0.08,0.50,0.43,0.72,0.73,0.54,0.07,-100$

9010 REM DATA 981.51

9100 REM P(i)

9110 REM DATA $325.85,249,29,149,96,113,12,60,50,26,76,19,45,10,60,6.07,3.81$

9120 REM DATA $1.89,2.06,2.68,1.46,1.00,1.17,1.14,0.86,0.43,0.47$

9130 REM DATA $1.06,0.31,0.54,0.13,0.43,-100$

10010 REM DATA 1889.96

10100 REM $p(1)$

10110 REM DATA $2.87,3.52,65.00,225.59,285.49,432.89,371.73,174.99,112.88,52.99$

10120 REM DATA $20.58,19.06,19.00,19.08,15.63,14.18,10.66,9.32,8.52,7.59$

10130 REM DATA $5.91,4.96,2.47,2.78,1.32,0.96,-100$

11010 REM DATA 49.43

11100 REM $p(i)$

11110 REM DATA $7.89,11.52,9.33,6.58,5.27,2.33,2.08,1.66,0.69,0.36,0.48,0.63,0.61$

11120 REM DATA - 100

12010 DATA 1312.01

12100 REM $p(1)$

12110 DATA $20.75,26.02,27.74,35,06,54.89,110.43,184.53,223.12,128.84,147.15$

12120 DATA $115.96,87.41,51.02,33.99,15.95,17.50,18.18,8.11,5.36,-100$ 


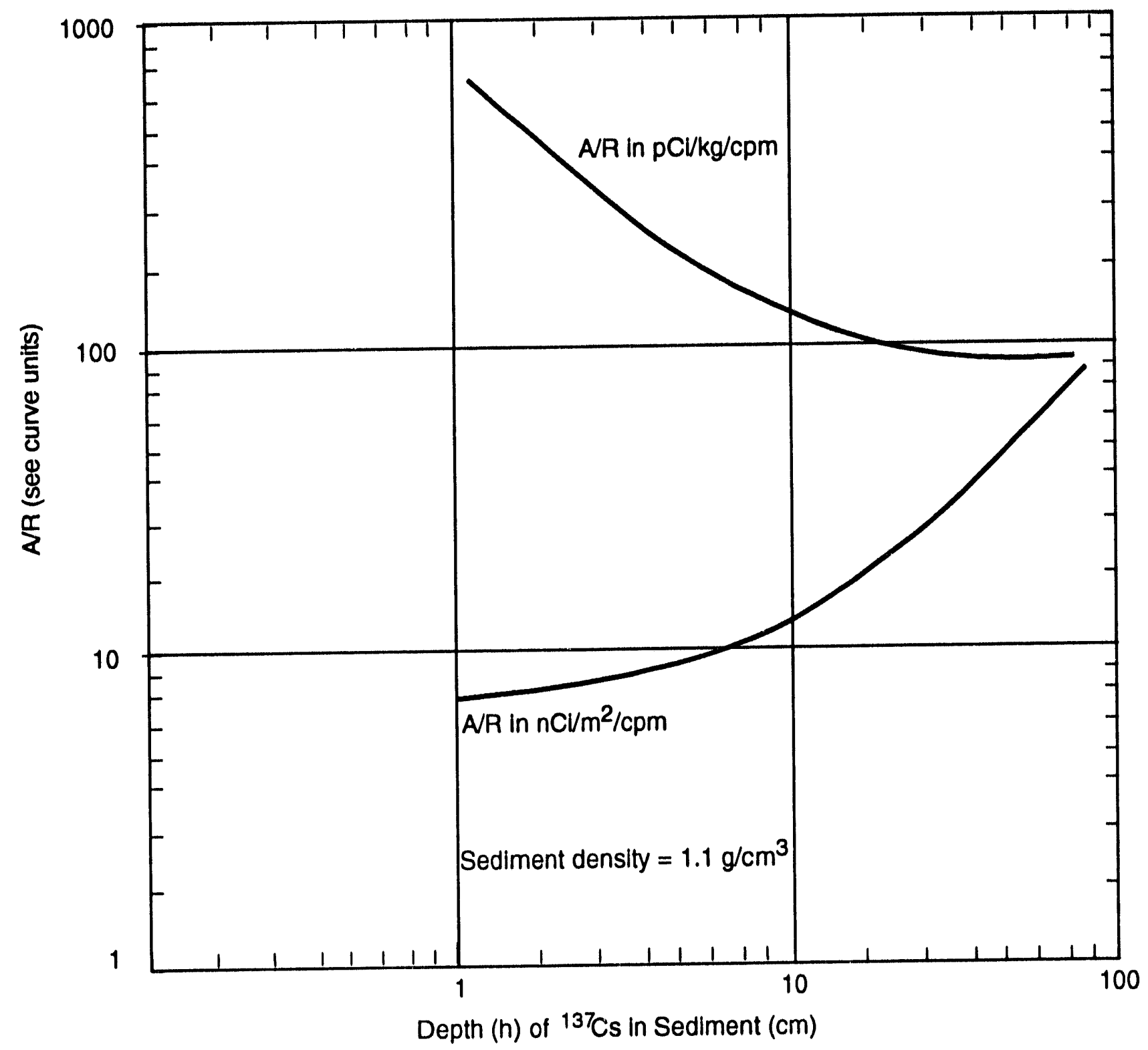

93X1494.14.AIL

Figure C-2. AR Conversion Factors of Uniform ${ }^{137} \mathrm{Cs}$ and Sediment as a Function of ${ }^{137} \mathrm{Cs}$ Depth (h). 


$$
\text { men }
$$

